\title{
Article \\ Central Role of Dendritic Cells in Pulmonary Arterial Hypertension in Human and Mice
}

\author{
Denise van Uden ${ }^{1}$, Thomas Koudstaal ${ }^{1}$, Jennifer A. C. van Hulst ${ }^{1}$, Ingrid M. Bergen ${ }^{1}$, Chelsea Gootjes ${ }^{1}$, \\ Nicholas W. Morrell ${ }^{2}$, Geert van Loo ${ }^{3,4}$, Jan H. von der Thüsen ${ }^{5}$ (D), Thierry P. P. van den Bosch ${ }^{(D)}$, \\ Maria-Rosa Ghigna ${ }^{6,7,8}$, Frédéric Perros ${ }^{6,7}$ (D), David Montani ${ }^{6,7,9}$ (D), Mirjam Kool ${ }^{1}$, Karin A. Boomars ${ }^{1, *,+}$ (D) \\ and Rudi W. Hendriks $1, *,+$
}

check for updates

Citation: van Uden, D.; Koudstaal, T.; van Hulst, J.A.C.; Bergen, I.M.; Gootjes, C.; Morrell, N.W.; van Loo, G.; von der Thüsen, J.H.; van den Bosch, T.P.P.; Ghigna, M.-R.; et al. Central Role of Dendritic Cells in Pulmonary Arterial Hypertension in Human and Mice. Int. J. Mol. Sci. 2021, 22, 1756. https://doi.org/ 10.3390/ijms22041756

Academic Editor: Marco Tatullo

Received: 12 January 2021

Accepted: 6 February 2021

Published: 10 February 2021

Publisher's Note: MDPI stays neutral with regard to jurisdictional claims in published maps and institutional affiliations.

Copyright: (c) 2021 by the authors. Licensee MDPI, Basel, Switzerland. This article is an open access article distributed under the terms and conditions of the Creative Commons Attribution (CC BY) license (https:/ / creativecommons.org/licenses/by/ $4.0 /)$.
1 Department of Pulmonary Medicine, Erasmus MC, University Medical Center Rotterdam, 3015 GD Rotterdam, The Netherlands; d.vanuden@erasmusmc.nl (D.v.U.); t.koudstaal.1@erasmusmc.nl (T.K.); j.vanhulst@erasmusmc.nl (J.A.C.v.H.); i.bergen@erasmusmc.nl (I.M.B.); chelsea.gootjes@hotmail.com (C.G.); m.kool@erasmusmc.nl (M.K.)

2 Department of Medicine, University of Cambridge \& NIHR BioResource for Translational Research \& Addenbrooke's Hospital NHS Foundation Trust \& Royal Papworth Hospital NHS Foundation Trust, Cambridge CB2 0QQ, UK; nwm23@cam.ac.uk

3 VIB Center for Inflammation Research, 9052 Ghent, Belgium; geert.vanloo@irc.vib-ugent.be

4 Department of Biomedical Molecular Biology, Ghent University, 9052 Ghent, Belgium

5 Department of Pathology, Erasmus MC, University Medical Center Rotterdam, 3015 GE Rotterdam, The Netherlands; j.vonderthusen@erasmusmc.nl (J.H.v.d.T.); t.vandenbosch@erasmusmc.nl (T.P.P.v.d.B.)

6 School of Medicine, Université Paris-Saclay, 94270 Le Kremlin-Bicêtre, France; mrghigna@gmail.com (M.-R.G.); frederic.perros@gmail.com (F.P.); davidmontani@gmail.com (D.M.)

7 INSERM UMR_S 999, Pulmonary Hypertension: Pathology and Novel Therapies, Hôpital Marie Lannelongue, 92350 Le Plessis Robinson, France

8 Division of Pathology, Marie Lannelongue Hospital, 92350 Le Plessis Robinson, France

9 Department of Respiratory and Intensive Care Medicine, Pulmonary Hypertension National Referral Center, Assistance Publique-Hôpitaux de Paris (AP-HP), Hôpital Bicêtre, 94270 Le Kremlin-Bicêtre, France

* Correspondence: k.boomars@erasmusmc.nl (K.A.B.); r.hendriks@erasmusmc.nl (R.W.H.); Tel.: +316-50031911 (K.A.B.); +31-10-7043700 (R.W.H.)

+ Co-senior authors.

Abstract: The pathogenesis of idiopathic pulmonary arterial hypertension (IPAH) is not fully understood, but evidence is accumulating that immune dysfunction plays a significant role. We previously reported that 31-week-old Tnfaip $3^{D N G R 1-K O}$ mice develop pulmonary hypertension (PH) symptoms. These mice harbor a targeted deletion of the TNF $\alpha$-induced protein-3 (Tnfaip3) gene, encoding the NF- $\kappa B$ regulatory protein A20, specifically in type I conventional dendritic cells (cDC1s). Here, we studied the involvement of dendritic cells (DCs) in $\mathrm{PH}$ in more detail. We found various immune cells, including DCs, in the hearts of Tnfaip3 ${ }^{D N G R 1-K O}$ mice, particularly in the right ventricle (RV). Secondly, in young Tnfaip $3^{D N G R 1-K O}$ mice, innate immune activation through airway exposure to toll-like receptor ligands essentially did not result in elevated RV pressures, although we did observe significant RV hypertrophy. Thirdly, PH symptoms in Tnfaip3 $3^{D N G R 1-K O}$ mice were not enhanced by concomitant mutation of bone morphogenetic protein receptor type 2 (Bmpr2), which is the most affected gene in PAH patients. Finally, in human IPAH lung tissue we found co-localization of DCs and CD8+ T cells, representing the main cell type activated by cDC1s. Taken together, these findings support a unique role of cDC1s in $\mathrm{PAH}$ pathogenesis, independent of general immune activation or a mutation in the Bmpr2 gene.

Keywords: pulmonary arterial hypertension; dendritic cells; inflammation; Tnfaip3; BMPR2; Tolllike receptor 


\section{Introduction}

Pulmonary arterial hypertension $(\mathrm{PAH})$ is characterized by structural remodeling of the arterial vasculature of the lung with a mean pulmonary arterial pressure (PAP) at rest of $\geq 20 \mathrm{mmHg}$, a mean capillary wedge pressure of $\leq 15 \mathrm{mmHg}$ and a pulmonary vascular resistance of $\geq 3$ Wood units [1]. This high pulmonary pressure causes hypertrophy of the right ventricle (RV), which can lead to heart failure and eventually death. Individuals with PAH are classified into World Health Organization (WHO) subgroups based on etiology and predisposing factors, such as genetic mutations classifying heritable PAH (HPAH) or systemic autoimmunity classifying connective tissue disease PAH (CTD-PAH). PAH patients with no known predisposing factors are classified as idiopathic PAH (IPAH) [1].

The major mutation found in HPAH patients is in the bone morphogenetic protein receptor type 2 (BMPR2) gene, causing loss of function or reduced receptor signaling (reviewed in [2]). BMPRII, which belongs to the transforming growth factor- $\beta$ (TGF $\beta$ ) receptor family, is expressed by various cell types, including vascular pulmonary endothelial cells and pulmonary artery smooth muscle cells (PASMCs), and is crucial in vascular homeostasis [3]. Reduced BMPRII signaling is associated with endothelial dysfunction and is not solely present in HPAH patients, but also in $14-35 \%$ of PAH patients-so-called sporadic cases without a known family history $[4,5]$. In the absence of a BMPR2 gene mutation, reduced BMPRII signaling can be induced by numerous causes, including aberrant activity of the immune system (reviewed in [6]). Conversely, not all patients with a BMPR2 mutation develop $\mathrm{PAH}$, indicating that additional factors are needed to cause disease.

Several lines of evidence support the critical involvement of the immune system in PAH pathogenesis. Firstly, blood expression profiling and transcriptomic studies in patients and in a rat model showed an enrichment of toll-like receptor (TLR) signaling [7-10]. PASMCs and dendritic cells (DCs) of the immune system use these TLRs to sense pathogens [11,12]. Specific TLR activation on PASMCs leads to the production of chemokines, such as the X-X-C-motif chemokine ligand 8 (CXCL8 or interleukin (IL)-8) and CXCL10 (IP-10), and endothelin-1, which may participate in PAH pathogenesis [11]. Infections with viruses such as HIV, human herpes virus 8 and hepatitis $B$ and $C$ are associated with PAH development [13]. Host defense to bacteria are also thought to contribute to disease by autoantigen-related molecular mimicry [14]. Nevertheless, only a minor proportion of infected individuals develop PAH. Secondly, serum levels of particular pro-inflammatory cytokines, including IL-6, IL-8, IL-10 and IL-12p70, are elevated in PAH patients and are inversely correlated with survival [15]. Unsupervised analysis of blood proteomic profiles showed that PAH patients have distinct immune phenotypes comprising multiple cytokines, chemokines and growth factors, which are independent of WHO subgroups and correlate with clinical risk $[15,16]$. Thirdly, lung biopsies from IPAH patients often contain accumulations of lymphoid cells that form tertiary lymphoid organs (TLOs) [17], in which DCs are present and crucial for TLO maintenance [18,19].

DCs form the bridge between the innate and adaptive immune system. They take up antigens and, after processing, present these to $T$ cells, thereby inducing an adaptive immune response. Several DC subsets exist under steady state conditions, including (i) plasmacytoid $\mathrm{DC}(\mathrm{pDC})$ which are known for their interferon production, (ii) type 1 conventional DCs (cDC1s) that excel in cross-presentation of antigens, and (iii) type 2 cDCs (cDC2s) which are known for CD4+ T cell induction [12]. Under inflammatory conditions, monocytes often differentiate to monocyte-derived-DCs (mo-DCs). Most of the DC subsets have been implicated in the pathobiology of IPAH and CTD-PAH (reviewed in [20]). CD209+ DCs are also massively recruited in remodeled arteries of IPAH patients and OX-62+ DCs accumulate with the same pattern in different rat models of severe pulmonary hypertension $(\mathrm{PH})$, induced by monocrotaline or exposure to SU5416 and hypoxia [21-23]. Importantly, not only is the abundance of DCs different between PAH patients and healthy individuals, but also their activation status [24-26]. Further support for the involvement of DCs comes from the Tnfaip $3^{D N G R 1-K O}$ mouse model, in which the TNF $\alpha$-induced protein-3 (Tnfaip3) gene encoding the A20 protein, a negative regulator of the nuclear factor kappa 
B (NF-kB) signaling pathway, is deleted in DCs using the Cre-LoxP system [27]. In this model, the Tnfaip3 gene is mainly targeted in cDC1s, whereby Cre expression is driven by the Dngr1 promoter. Tnfaip $3^{D N G R 1-K O}$ mice spontaneously develop PH over time and show lymphocytic infiltration and vascular remodeling [27].

The exact mechanism by which Tnfaip $3^{D N G R 1-K O}$ mice develop PH symptoms and the importance of the altered activation status of DCs or other immune cells in this model is not known. In our previous study we closely investigated the $\mathrm{PH}$ phenotype and the immunological landscape of the lungs of Tnfaip $3^{D N G R 1-K O}$ mice. In this study we first characterized the immunological landscape of the heart in Tnfaip $3^{D N G R 1-K O}$ mice. Moreover, since signs of PH are absent in young Tnfaip3 $3^{D N G R 1-K O}$ mice, we wondered whether additional triggers might promote earlier development of the $\mathrm{PH}$ phenotype. Therefore, we investigated the effects of immune activation on PH development and lung inflammation by airway exposure to TLR ligands in vivo. By crossing Tnfaip $3^{D N G R 1-K O}$ mice with $B m p r 2^{+/ R 899 X}$ mice, we determined whether a vascular trigger would result in enhancement of the PH phenotype. Finally, we explored the relevance of our findings by determining DC and CD8+ T cell co-localization in human IPAH lung tissue.

\section{Results}

\subsection{Increased Myocardial Infiltration of Dendritic Cells in the RV of Tnfaip $3^{D N G R 1-K O}$ Mice}

Tnfaip $3^{D N G R 1-K O}$ mice show increased RV pressures, RV hypertrophy and increased numbers of pulmonary DCs [27]. Flow cytometric analysis showed an increase in the proportions of DCs in the RV and of T cells in both the RV and left ventricle (LV) of Tnfaip $3^{\text {DNGR1-KO }}$ mice, compared with wild-type (WT) control mice at 31 weeks of age (Figure 1a, Supplementary Figure S1). The increase in the proportions of DCs and T cells was supported by RT-PCR analysis for the expression of the DC markers CD11c and basic leucine zipper transcriptional factor ATF-like 3 (BATF3), and the T cell subset markers $\mathrm{CD} 4$ and CD8, respectively (Figure $1 \mathrm{~b}$ ). To confirm the presence of DCs in the RV, we performed histological analysis on the RV of Tnfaip $3^{D N G R 1-K O}$ and WT mice. Strikingly, in contrast to WT control mice, we found high number of DCs that were $\mathrm{YFP}^{+}$, indicating Tnfaip3 gene deletion in the RV of Tnfaip $3^{D N G R 1-K O}$ mice from 14 weeks of age onwards (Figure 1c). An Elastin van Gieson (EvG) staining for collagen and vascular intima wall thickening in heart tissue showed signs of lymphocytic infiltration and RV hypertrophy in 24-week-old Tnfaip $3^{\text {DNGR1-KO }}$ mice without evidence for myocardial vascular remodeling, when compared to WT mice (Figure 1d).

Thus, in Tnfaip $3^{D N G R 1-K O}$ mice, lymphocyte infiltration was observed in both ventricles and myocardial DC infiltration in the RV was present from 14 weeks onwards.

\subsection{TLR4 Activation Leads to RV Hypertrophy but Not to Increased RV Pressures in Young Tnfaip $3^{\text {DNGR1-KO }}$ Mice}

The first signs of immune cell involvement in the Tnfaip $3^{D N G R 1-K O}$ mice were already present at 14 weeks of age when the right ventricular systolic pressure (RVSP) was not yet elevated (Figure 1a). Since bacteria and viruses may be inducers of PAH [13,14], we wondered if an additional inflammatory trigger, such as exposure to TLR ligands, would result in development of $\mathrm{PH}$ at younger age. Therefore, 11-13-week-old Tnfaip 3 DNGR1-KO were intratracheally (i.t.) challenged with TLR4 ligand lipopolysaccharide (LPS), TLR3 ligand polyinosinic-polycytidylic acid (Poly I:C) or TLR9 ligand CpG, which was repeated after 7 days (Figure 2a). Two weeks after the last exposure, mice were analyzed for RV pressures, RV hypertrophy and immune cell involvement. In these experiments, LPStreated or saline $(\mathrm{NaCl})$-treated WT mice were included as controls. 
(a)

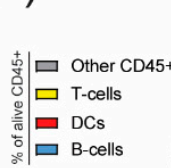

(b)

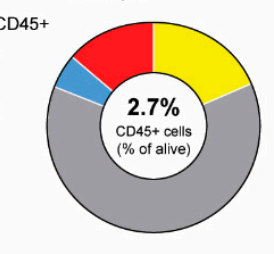

Right ventricle

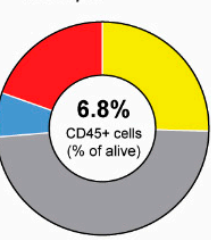

Left ventricle Tnfaip3 $3^{\text {DNGR1-WT }} \quad$ Tnfaip3 ${ }^{\text {DNGR1-KO }}$

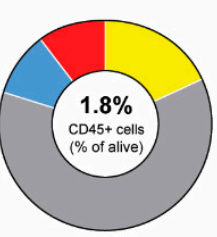

(c)
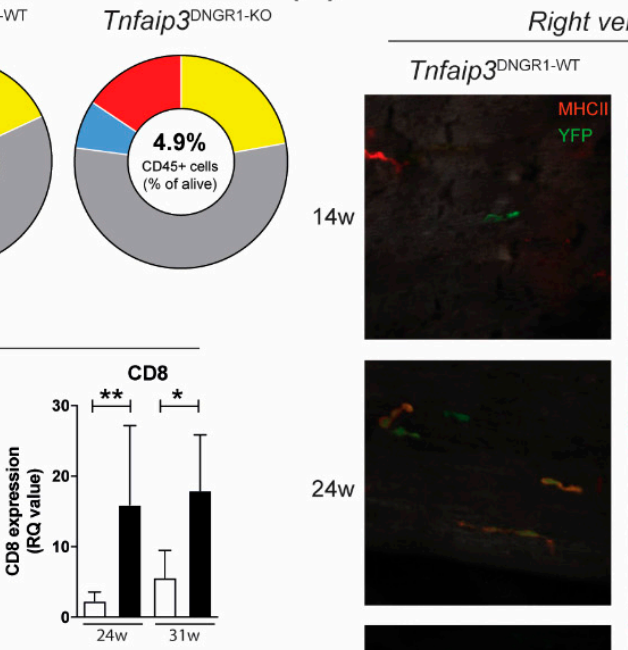

Left ventricle
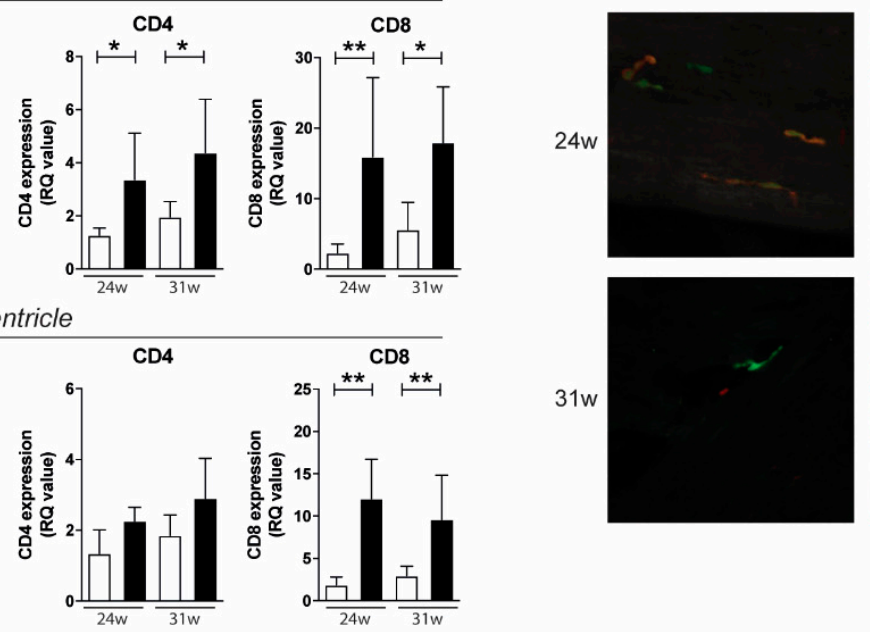
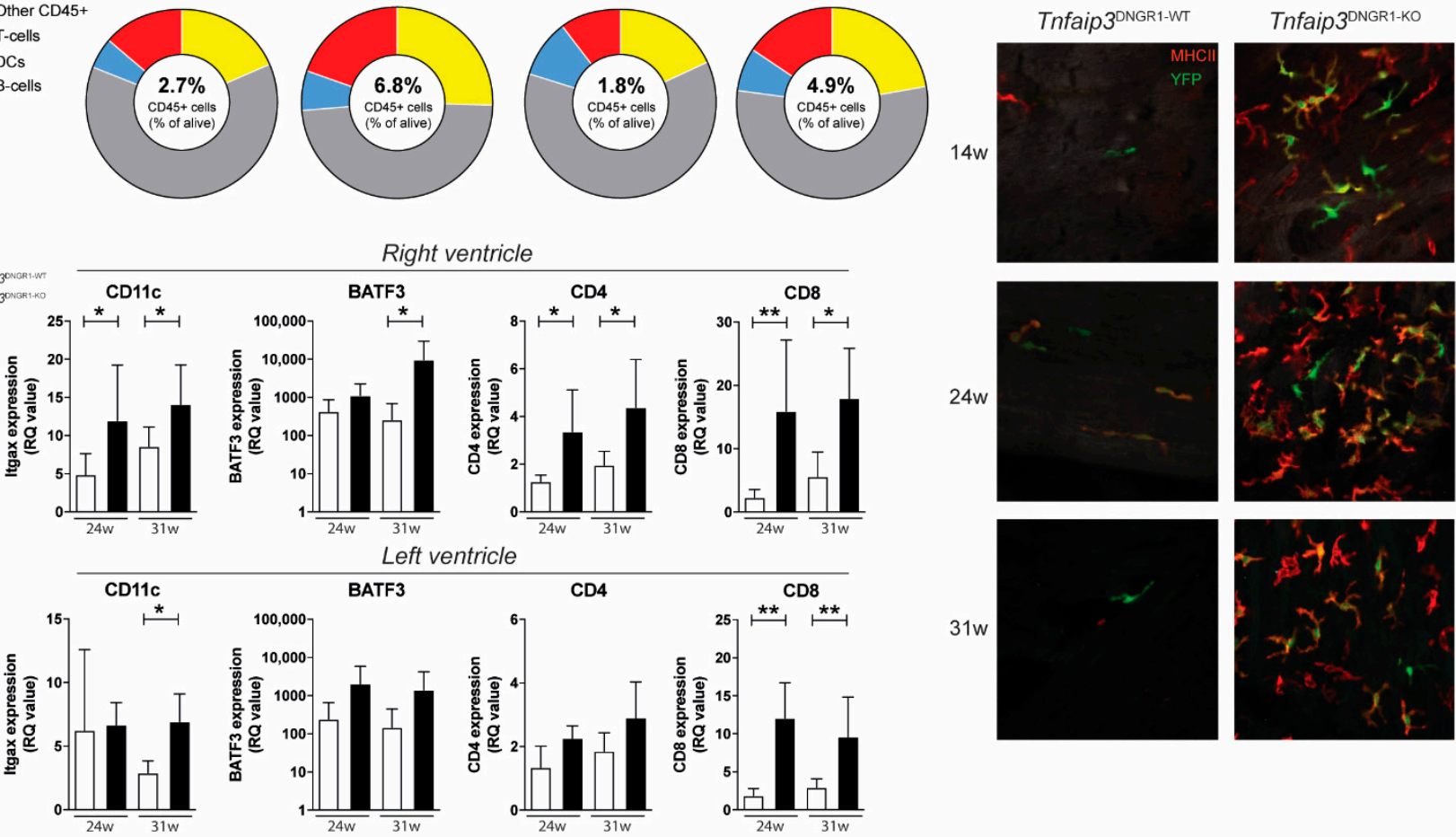

$24 w$

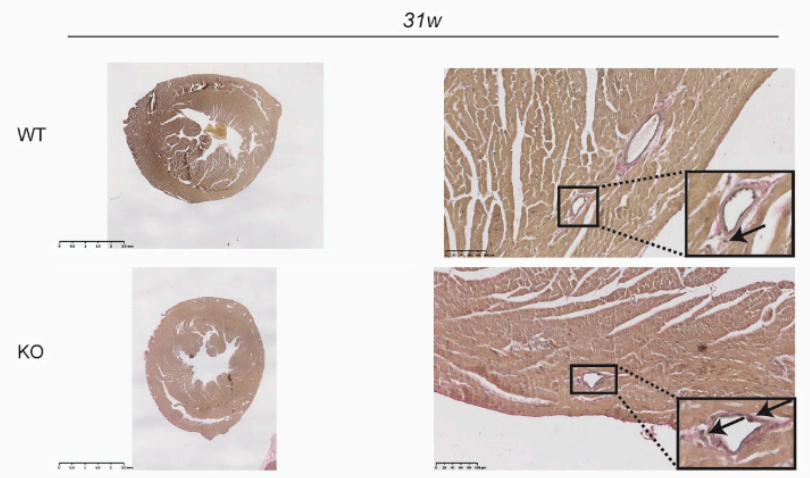

$31 w$

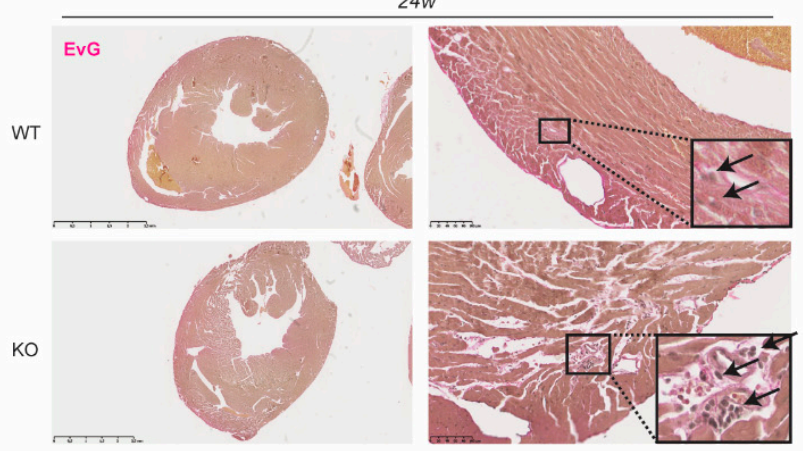

Figure 1. Increased myocardial infiltration of dendritic cells (DCs) in the right ventricle (RV) of Tnfaip $3^{D N G R 1-K O}$ mice. (a) Flow cytometry analysis for CD45+ cells (alive CD45 ${ }^{+}$cells), DCs (CD3-/CD19-, MHC-II+CD11c+), T cells (CD3+) and $\mathrm{B}$ cells (CD19+) in separately measured right and left ventricle cell suspensions from hearts of Tnfaip $3^{D N G R 1-W T / K O}$ mice; (b) mRNA expression (relative to the glyceraldehyde-3-phosphate dehydrogenase (GAPDH) housekeeping gene) of DC markers CD11c and BATF3, and the T cell subset markers CD4 and CD8 in 24- and 31-week-old Tnfaip3 ${ }^{\text {DNGR1-KO }}$ and wild-type (WT) control mice; (c) whole mount analysis of right ventricle staining for YFP (green) and MHCII (red) in age 14-, 24- or 31-week-old Tnfaip3 ${ }^{D N G R 1-K O}$ mice. Results are presented as mean values + standard deviations of 4-6 mice per group. ${ }^{*} p<0.05,{ }^{* *} p<0.01$; (d) Elastin van Gieson (EvG)-stained whole heart section histology of Tnfaip3 ${ }^{D N G R 1-W T}$ and Tnfaip3 $3^{D N G R 1-K O}$ mice for representative sections. Scale in left panels is $2.5 \mathrm{~mm}$ and in right panels $100 \mu \mathrm{m}$. Arrows indicate lymphocytes. 
(a)

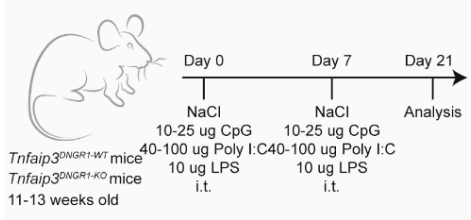

(b)

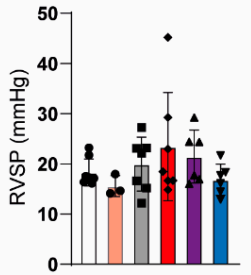

(c)

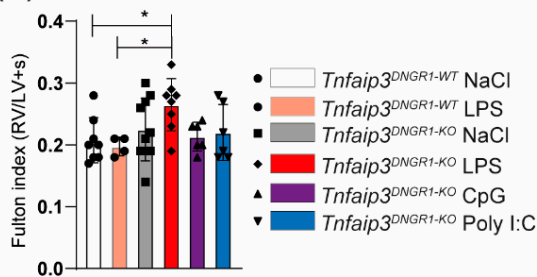

(d)

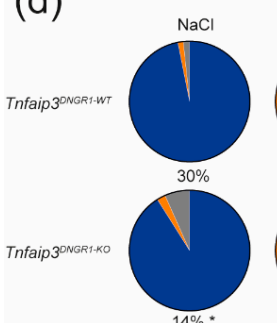

(g)
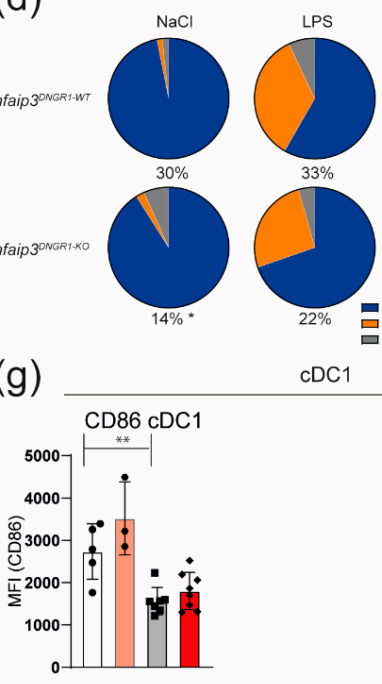

$\mathrm{cDC}$

(e)
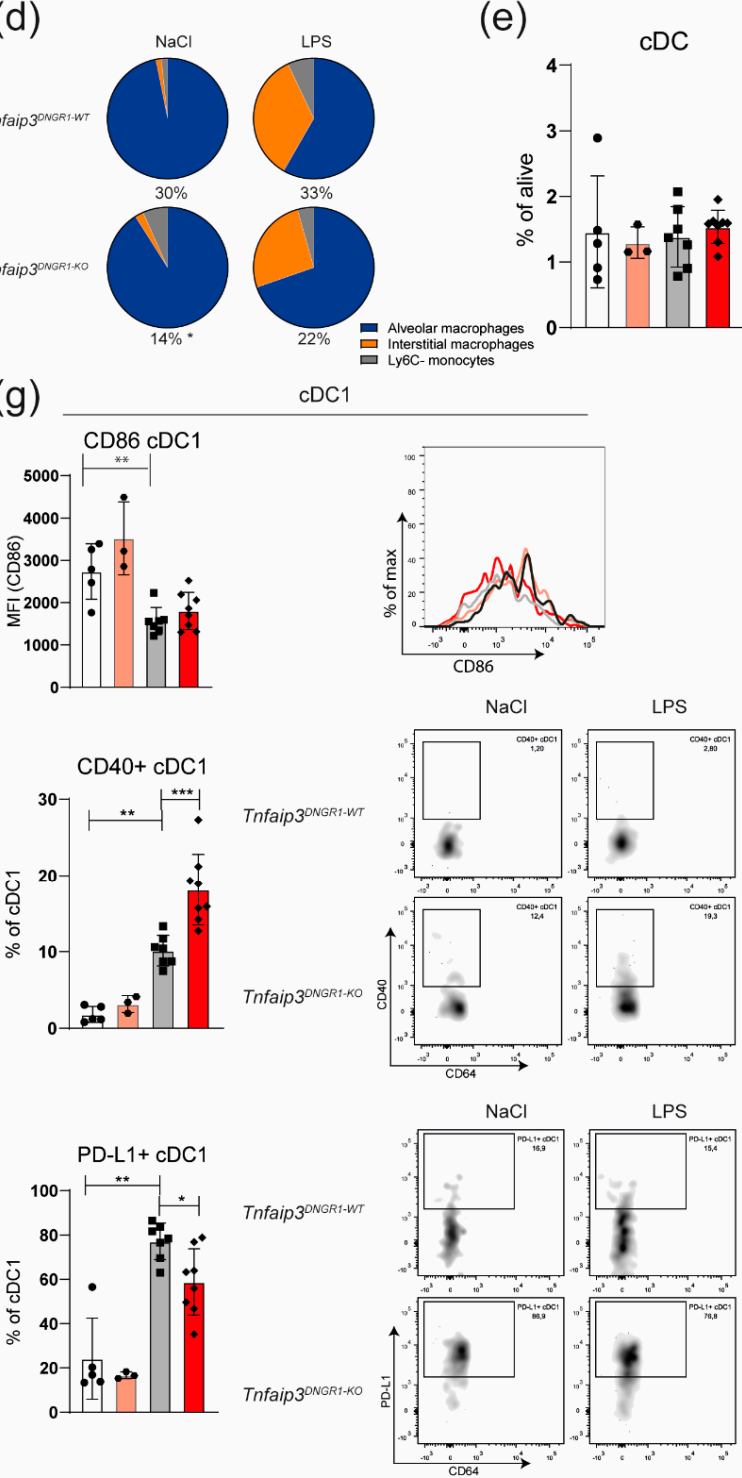

(f) $\mathrm{CDC} 1 / \mathrm{cDC} 2$

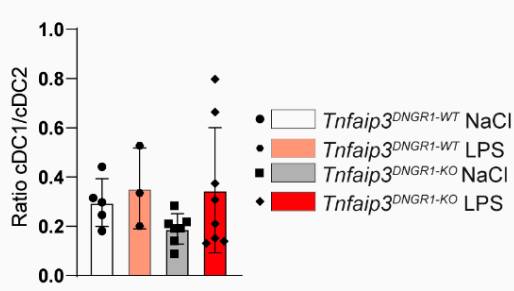

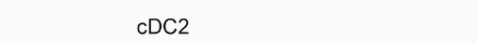

CD86 cDC2

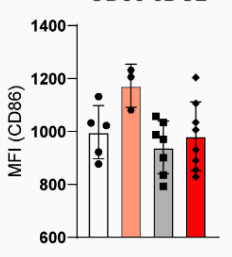

$\mathrm{CD} 40+\mathrm{CDC} 2$
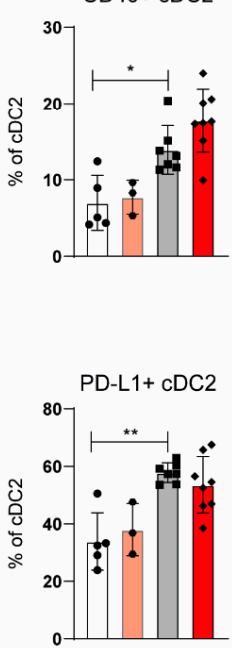

Figure 2. TLR4 activation leads to RV hypertrophy and $C D C 1$ phenotype changes in Tnfaip $3^{D N G R 1-K O}$ mice. (a) Scheme of intratracheal (i.t.) administration of $\mathrm{CpG}$, lipopolysaccharide (LPS) and polyinosinic-polycytidylic acid (Poly I:C) in WT and Tnfaip $3^{\text {DNGR1-KO }}$ mice on day 0 and 7, and analysis on day 21; (b) right ventricular systolic pressure (RVSP) in toll-like receptor (TLR)-exposed WT and Tnfaip $3^{D N G R 1-K O}$ mice, determined by right heart catheterization; (c) hypertrophy of RV measured by Fulton index (right ventricle/ left ventricle + septum); (d) assessment of the indicated cell types in LPS-exposed WT and Tnfaip $3^{D N G R 1-K O}$ mice. Proportion of the $\mathrm{CD} 64^{+} \mathrm{GR} 1^{-}$macrophage/monocyte population from total alive cells is indicated below the pie charts; (e,f) quantification of total DCs (e) and the CD103+ cDC1/CD11b+ cDC2 subset ratio (f) in the lungs of the indicated mice, as determined by flow cytometry; (g) quantification of surface CD86, CD40 and PD-L1 expression on CD103+ cDC1s (left) and CD11b + cDC2s (right) in the indicated mouse groups. Flow cytometry analyses are shown as histogram overlays of CD86 expression (top), as dot plots with CD64/CD40 profiles (middle) and dot plots with CD64/PD-L1 profiles (bottom) of gated CDC1s. Results are presented as mean values + standard deviation of 3-10 mice $(\mathbf{b}, \mathbf{c})$ or 3-6 (e-g) mice per group. MFI = median fluorescence intensity. ${ }^{*} p<0.05,{ }^{* *} p<0.01,{ }^{* * *} p<0.001$. 
Administration of LPS or Poly I:C, but not CpG, induced weight loss in Tnfaip3 $3^{D N G R 1-K O}$ mice (Supplementary Figure S2). This was also seen following LPS administration in WT mice. Exposure of Tnfaip $3^{D N G R 1-K O}$ mice to TLR ligands did not result in increased RV pressures, compared to saline-treated Tnfaip $3^{D N G R 1-K O}$ or WT mice that were administered saline or LPS (Figure 2b). However, in LPS-exposed Tnfaip $3^{D N G R 1-K O}$ mice, the RV was larger than in Tnfaip $3^{D N G R 1-K O}$ mice treated with saline, Poly I:C or CpG, or in LPS- or saline-treated WT mice (Figure 2c). As shown by EvG staining (Supplementary Figure S3), pulmonary vessels of LPS-exposed Tnfaip $3^{D N G R 1-K O}$ and WT mice appeared to be thickened compared to saline-treated WT mice. Moreover, LPS exposure in Tnfaip $3^{D N G R 1-K O}$ mice led to inflammatory infiltrates around the vessels. Thus, LPS exposure alone was not sufficient to cause elevation of the Fulton index, but in combination with the altered immune system in Tnfaip $3^{D N G R 1-K O}$ mice, this was sufficient.

In these analyses, we found that the total population of monocytes/macrophages, which have also been implicated in PH pathogenesis [28], was decreased in saline- or LPSexposed Tnfaip $3^{D N G R 1-K O}$ mice (14 and 22 percent, respectively) compared to WT control mice (30 and 33 percent, respectively) (Figure 2d, see for gating: Supplementary Figure S4a). The induction of immune activation by LPS in Tnfaip $3^{D N G R 1-K O}$ and WT mice was confirmed by the observation of increased proportions of interstitial macrophages (IM) in the lung [29] (Figure 2d).

The frequency of pulmonary cDCs or the $\mathrm{CDC} 1 / \mathrm{cDC} 2$ ratio in Tnfaip $3^{\mathrm{DNGR} 1-K O}$ and WT mice did not significantly change after LPS exposure (Figure 2e,f; see for gating: Supplementary Figure S4b). Consistent with our reported findings in 31-week-old mice [27], we found altered expression of the cell surface markers CD86, CD40 and PD-L1 on CDCs in 14-17-week-old Tnfaip $3^{D N G R 1-K O}$ mice, compared to WT mice (Figure 2g). LPS exposure increased CD40 and reduced PD-L1 expression but did not affect CD86 expression on cDC1s in the lungs of Tnfaip $3^{D N G R 1-K O}$ mice. These changes in activation marker expression 2 weeks following LPS exposure were not seen in cDC2s in Tnfaip $3^{D N G R 1-K O}$ mice, nor in either subset in WT mice (Figure 2g).

In summary, TLR stimulation-mimicking bacterial or viral infection-did not lead to increased RV pressures and therefore did not appear to promote a $\mathrm{PH}$ phenotype in young Tnfaip $3^{D N G R 1-K O}$ mice. However, LPS exposure in Tnfaip $3^{D N G R 1-K O}$ mice was associated with RV hypertrophy and an altered surface phenotype of cDC1s but not cDC2s in the lung.

\subsection{The PH Phenotype of Tnfaip $3^{D N G R 1-K O}$ Mice Is Not Enhanced by Concomitant BMPR2 Mutation}

Next, we wondered if involving structural cells would result in the enhancement of the PH phenotype in Tnfaip3 ${ }^{D N G R 1-K O}$ mice. To this end, we employed Bmpr $2^{+/ R 899 X}$ mice, harboring a heterozygous knock-in allele of the R899X mutation as is seen in HPAH patients, which results in a premature stop codon [30,31]. These mice develop spontaneous $\mathrm{PH}$ by the age of 6 months, likely due to defective BMPRII expression in pulmonary endothelial cells [31].

The Tnfaip $3^{D N G R 1-K O}$ mice were crossed with $B m p r 2^{+/ R 899 X}$ mice and analyzed at 31 weeks. Compared to WT mice, RV pressure was significantly increased in Tnfaip $3^{\text {DNGR1-KO }}$ mice, but not in $B m p r 2^{+/ R 899 X}$ or Tnfaip $3^{D N G R 1-K O} \times \mathrm{Bmpr}^{+/ R 899 \mathrm{X}}$ mice (Figure 3a). In all three mutant mouse groups the Fulton index was significantly higher than in WT mice (Figure 3a). A hematoxylin and eosin (H\&E) staining showed that both Tnfaip $3^{\text {DNGR1-KO }}$ and Tnfaip3 $3^{D N G R 1-K O} \times \mathrm{Bmpr}^{+/ R 899 X}$ mice had signs of inflammatory infiltrates, which were not seen in WT and Bmpr2 ${ }^{+/ R 899 X}$ mice (Supplementary Figure S5). Thickening of the small and mid-sized pulmonary vessels was evident in all three mutant mouse groups (shown by EvG and $\alpha$ smooth muscle actin ( $\alpha$-SMA) staining in Supplementary Figure S5). However, the RV pressures were only increased in Tnfaip $3^{D N G R 1-K O}$ mice (Figure 3a). 
(a)

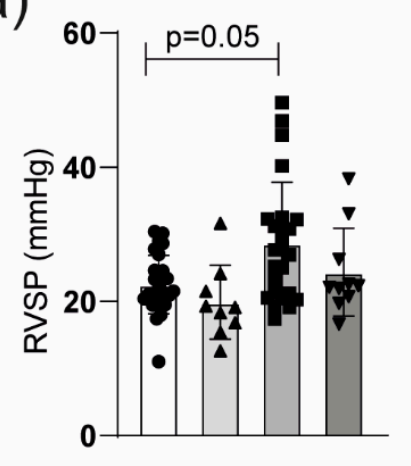

(b)

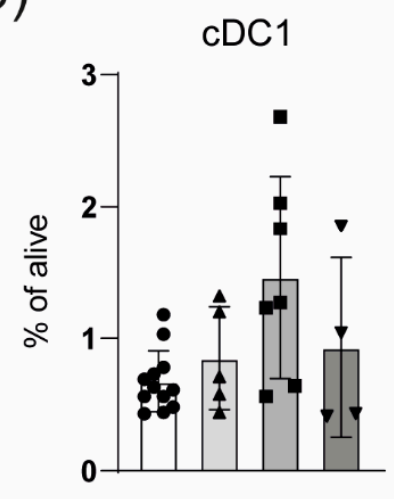

(d)

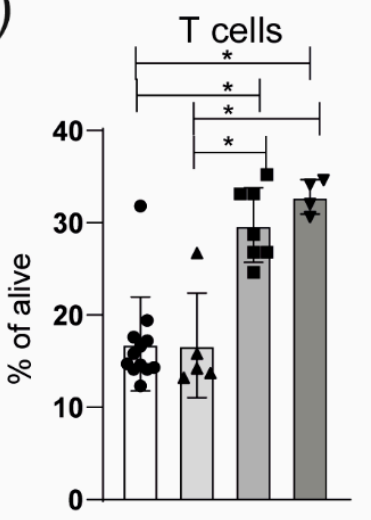

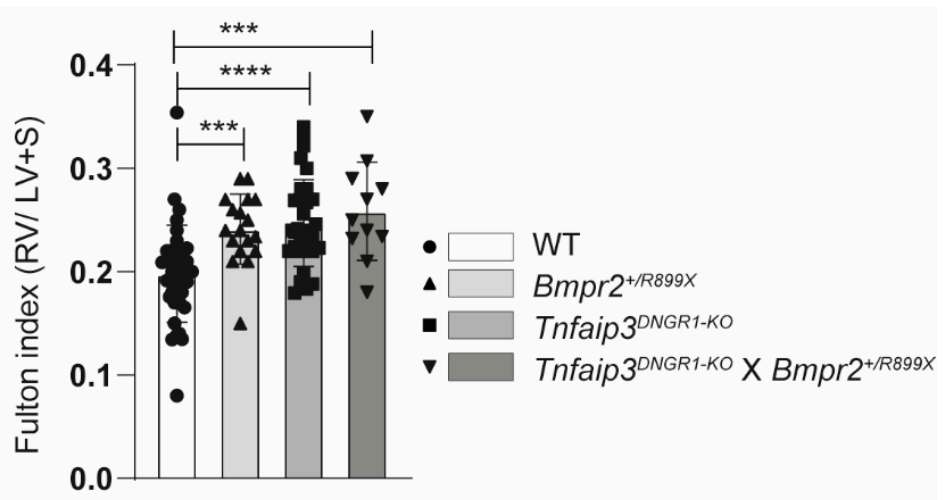

(c)

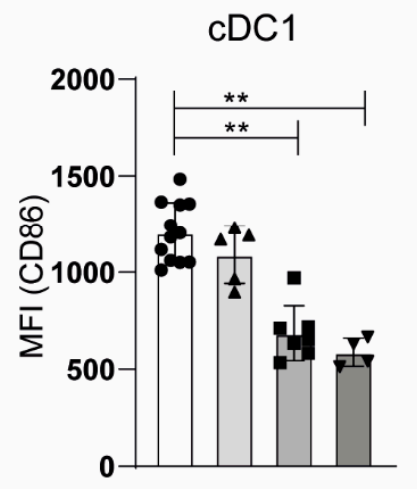

(e)

memory CD8+ T cells

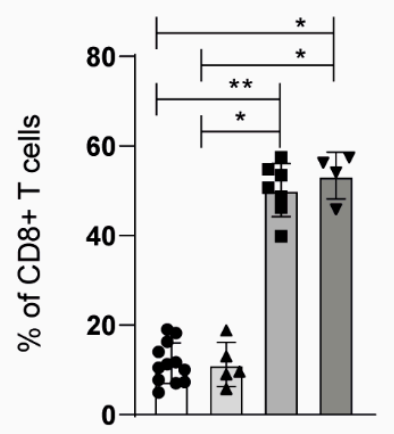

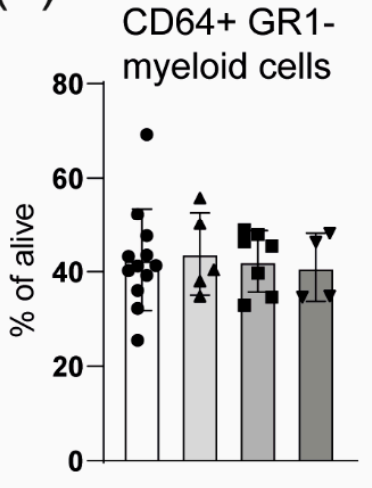

(f)

B cells

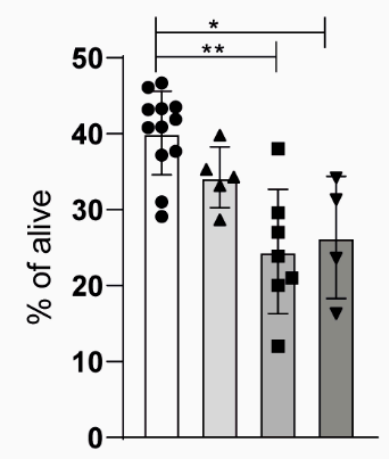

Figure 3. Concomitant Bmpr2 mutation does not alter the pulmonary hypertension (PH) phenotype in Tnfaip $3^{D N G R 1-K O}$ mice. (a) Right ventricular systolic pressure (RVSP), determined by right heart catheterization and hypertrophy of RV measured by Fulton index (right ventricle/ left ventricle + septum) of the indicated mouse groups; (b) quantification of lung CD103+CD11c+ cDC1 frequencies and CD86 expression (MFI = median fluorescence intensity) by flow cytometry; (c-f) quantification of CD64+GR1- monocyte/macrophage population (c), CD3+ T cells (d), memory CD44+CD62L- CD8+ $\mathrm{T}$ cells (e) or CD19+ B cells (f) determined by flow cytometry in the lungs of the indicated mouse groups. Results are presented as mean + standard deviation of 10-31 mice (a) or 4-12 mice (b-e) per group. ${ }^{*} p<0.05,{ }^{* *} p<0.01,{ }^{* * *} p<0.001$, $* * * * p<0.0001$.

We subsequently investigated whether the $B m p r 2^{+/ R 899 X}$ genotype affected immune cells in the lung. The frequency of the $\mathrm{CDC} 1$ subset was similar across the different mouse groups (Figure $3 b)$. Surface CD86 expression on cDC1s was specifically reduced in Tnfaip $3^{\text {DNGR1-KO }}$ mice, irrespective of the Bmpr2 genotype (Figure $3 \mathrm{~b}$ ). In all three mutant mouse groups, the CD64+GR1- macrophage/monocyte populations were unaltered (Figure 3c). The proportions of $\mathrm{T}$ cells in the lung were significantly increased in Tnfaip $3^{D N G R 1-K O}$ mice, irrespective of the Bmpr2 genotype (Figure 3d). Hereby, the proportions of CD4+ and CD8+ T cells were similar 
in the four mouse groups (Supplementary Figure S6). The proportions of CD44+CD62Lmemory cells within the CD8+ T cell population were increased in Tnfaip $3^{D N G R 1-K O}$ mice, irrespective of the Bmpr2 genotype (Figure 3e). Finally, the frequency of pulmonary B cells was slightly lower in Tnfaip $3^{D N G R 1-K O}$ mice, irrespective of the Bmpr2 genotype, compared to WT or Bmpr2 $2^{+/ R 899 X}$ mice (Figure 3f).

Overall, Tnfaip3 ${ }^{D N G R 1-K O} \times$ Bmpr $^{+/ R 899 X}$ mice did not show increased RV pressure and immunologically paralleled the Tnfaip $3^{D N G R 1-K O}$ mice. From these findings we conclude that Tnfaip $3^{D N G R 1-K O} \mathrm{cDC} 1$ cells have a unique and dominant ability to induce $\mathrm{PH}$ symptoms, which is not modulated or enhanced by aberrant pulmonary endothelial cells in $\mathrm{Bmpr}^{+/ R 899 X}$ mice.

\subsection{DCs and CD8+ T Cells Co-Localize around Blood Vessels in Lungs of IPAH Patients}

The $\mathrm{CDC} 1$ subset excels in cross presentation and is known for its ability to activate CD8 + T cells [12]. Since cDC1s seem to have a unique and dominant ability to induce a PH phenotype, we determined the presence of DCs and CD8+ T cells in both Tnfaip $3^{\text {DNGR1-KO }}$ mice and human IPAH lung tissue by immunohistochemistry.

In the lungs of 31-week-old WT and Tnfaip $3^{D N G R 1-K O}$ mice, DCs and T cells were identified by CD11c and CD3 expression, respectively (Figure 4a,b). Although some of these cells were observed in the lung parenchyma, most of the DCs and T cells were located in the vicinity of blood vessels, and their numbers were increased in Tnfaip $3^{D N G R 1-K O}$ mice, as compared to WT mice (Figure $4 \mathrm{a}, \mathrm{b})$. In the lungs of Tnfaip $3^{D N G R 1-K O}$ mice, DCs often were in close proximity to CD3+ T cells. A fraction of these T cells were CD8+ T cells, as shown by the staining for CD8 (Figure 4c).

To determine co-localization of DCs with CD8+ T cells in the lungs of IPAH patients, we studied the presence of these cells by chromogenic multiplex immunohistochemistry in paraffin-embedded lung tissue of six IPAH patients. DCs express several mannose receptors such as CD209 and CD206, therefore we used the mannose receptor CD206 to identify DCs [12]. Since macrophages also express CD206 we co-stained for CD68, which is only expressed by macrophages to distinguish DCs (CD68-CD206+) from macrophages (CD68+CD206+). The multiplex staining further included staining for CD8, and for $\alpha$-SMA to identify blood vessel structures. In healthy lung tissue, the number of immune cells is generally limited, and immune cell infiltrates mostly consist of macrophages, while the numbers of DCs and CD8 cells are low (Figure 5a,b). Occasionally, we found CD8+ T cells close to CD68-CD206+ DCs (Shown for a control lung in Figure 5a,b). 
(a)

(b)
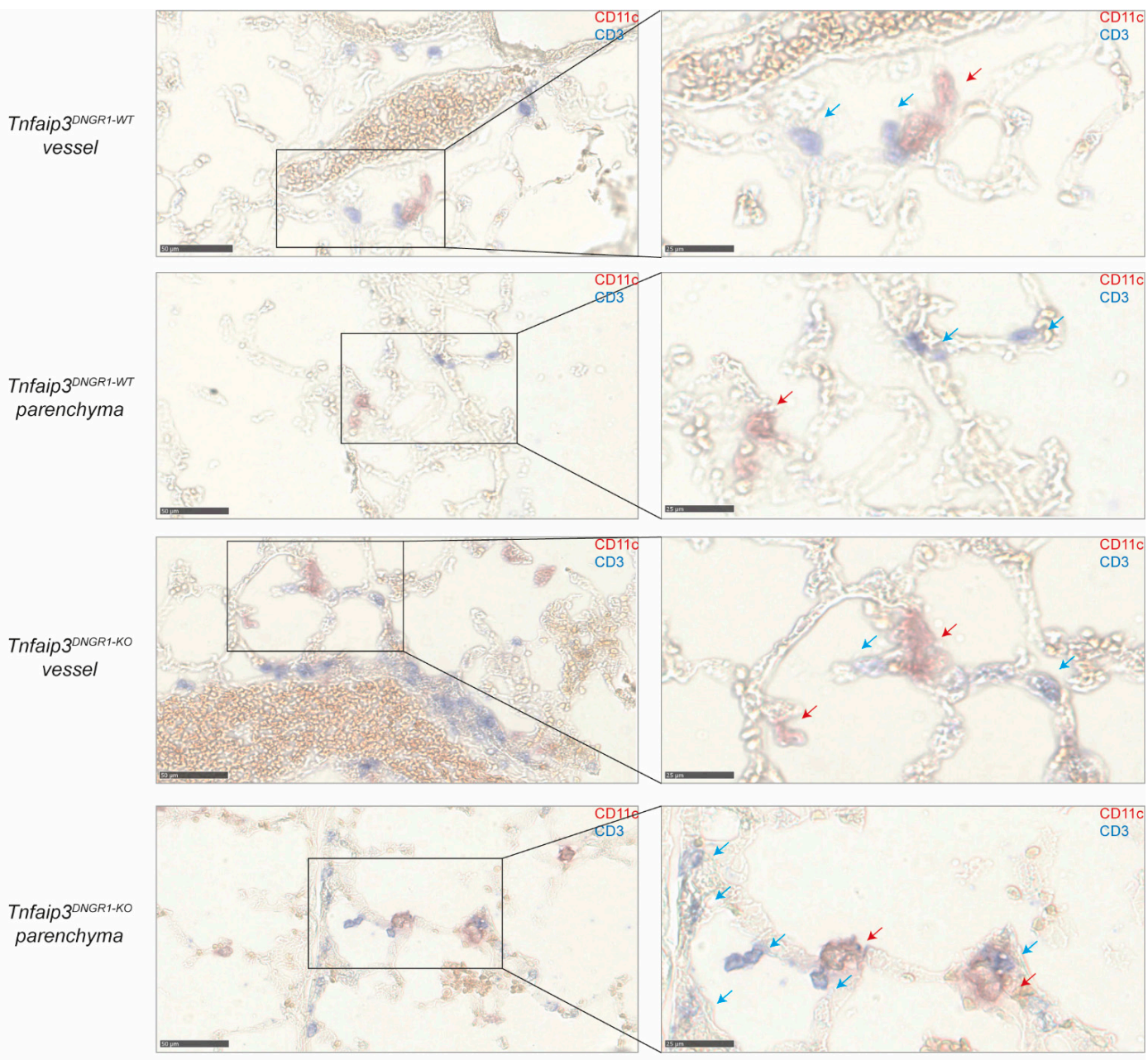

(c)

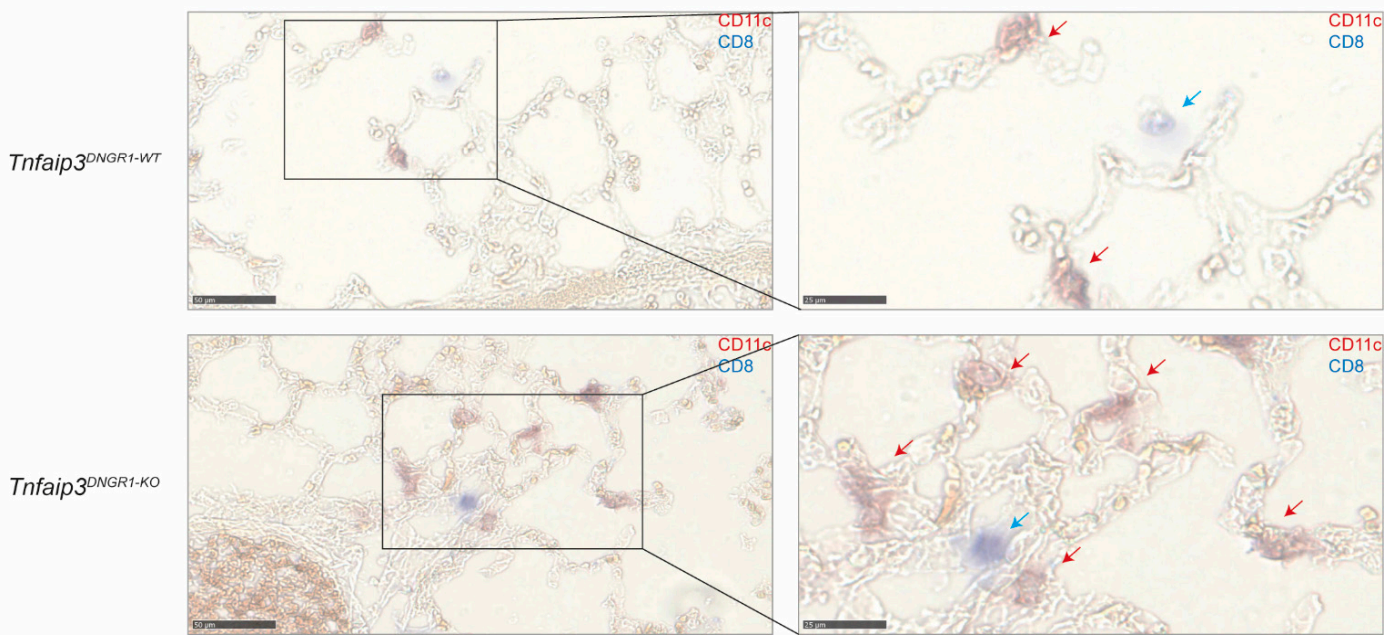

Figure 4. DCs and T cells are more often in close proximity around vessels and in parenchyma in Tnfaip $3^{D N G R 1-K O}$ mice. (a) DC (CD11c, red) and T cell (CD3, blue) staining on lung cryosections of 31-week-old WT mice of which an area around a vessel (top) and parenchyma (bottom) of the same mouse is depicted. Magnification of selected areas (right); (b) DC (CD11c, red) and T cell (CD3, blue) staining on lung cryosections of 31-week-old Tnfaip3 ${ }^{D N G R 1-K O}$ mice of which an area around a vessel (top) and parenchyma (bottom) of the same mouse is depicted. Magnification of selected areas (right); (c) DC (CD11c, red) and CD8+ T cells (CD8, blue) of WT (top) and Tnfaip3 ${ }^{D N G R 1-K O}$ (bottom) mice around a vessel. Magnification of selected area (right). Data shown are representative for 4-6 mice per group. Scale in left panels is $50 \mu \mathrm{m}$ and of right panels $25 \mu \mathrm{m}$. Blue arrows indicate T-cells, and red arrows indicate DCs in the larger magnification (right panels). 
(a)

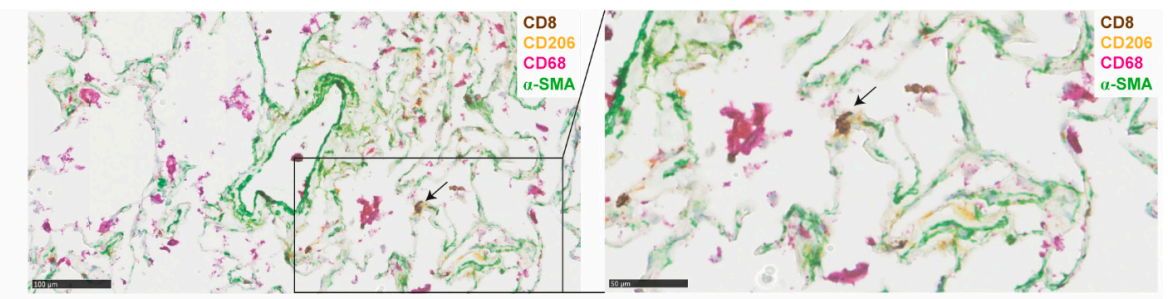

(b)

(b)
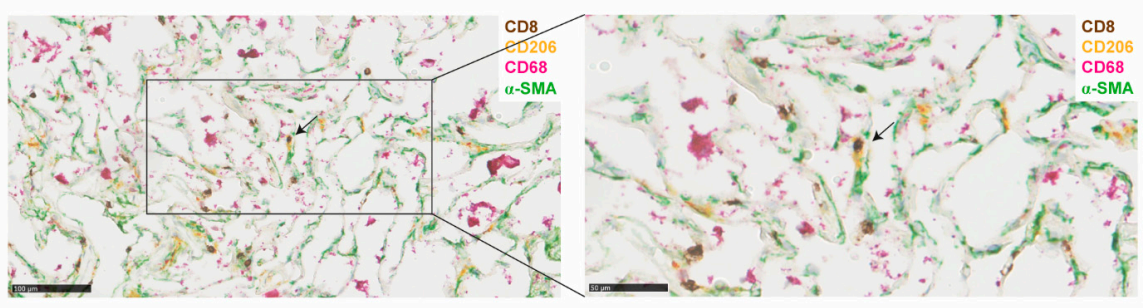

(c)

IPAH 1
fully occluded
vessel
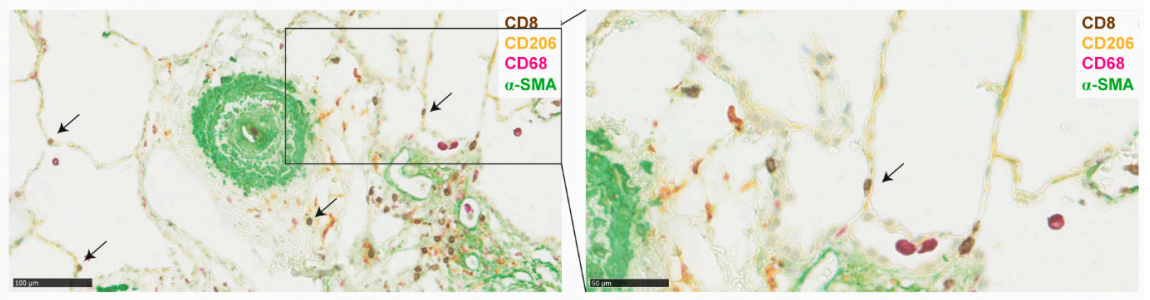

(d)
IPAH 1
partly occluded
vessel

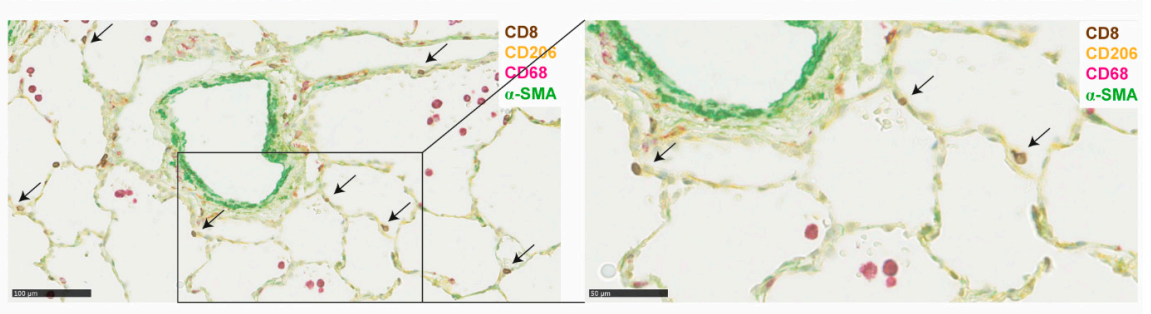

(e)

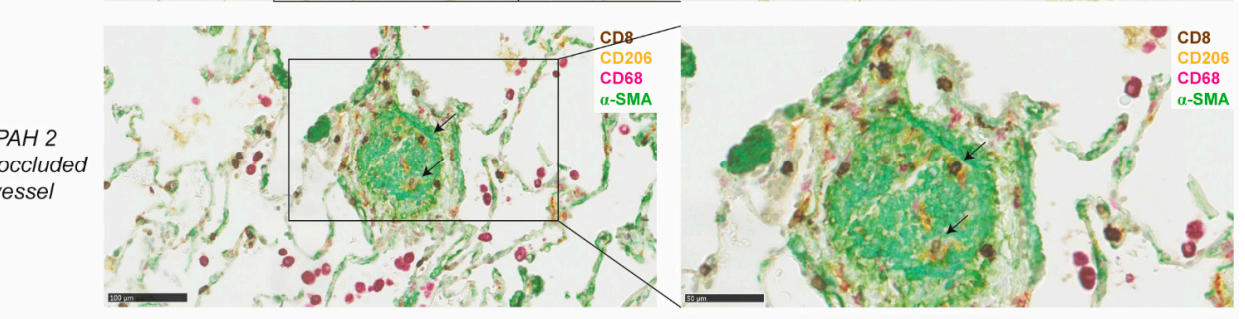

(f)

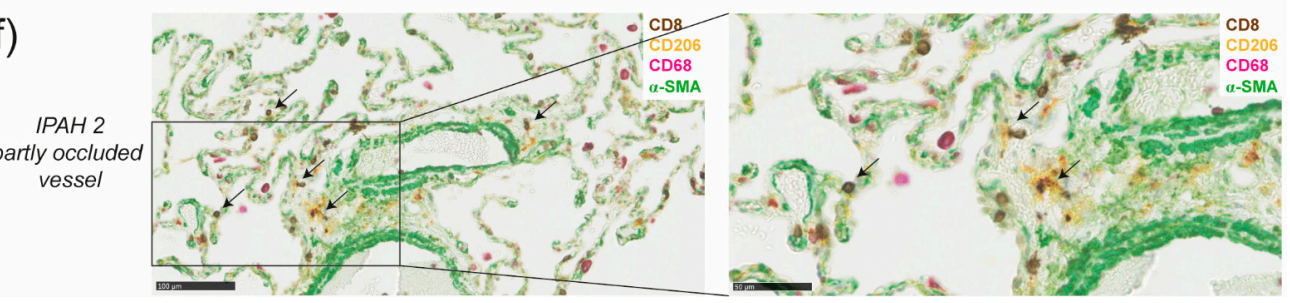

Figure 5. DCs are in close proximity to CD8+ T cells around vessels and in parenchyma in lungs of idiopathic pulmonary arterial hypertension (IPAH) patients. (a,b) 4-plex chromogenic multiplex staining of DCs (CD206+, yellow), macrophages (CD68+, purple with or without CD206), T cells (CD8, DAB) and $\alpha$-SMA (green) around a vessel and intraparenchymal (a) or in parenchyma (b) and the magnification of the indicated area (right) in the same healthy tissue from a smoking patient who was diagnosed with adenocarcinoma; (c,d) determination of DCs (CD206+CD68-), CD8+ T cells (CD8+), macrophages $(\mathrm{CD} 68+)$ and vessels ( $\alpha$-SMA) around a fully occluded vessel (c) or partly occluded vessel (d) and the magnification of the indicated area (right) of the same IPAH patient with moderate remodeling; $(\mathbf{e}, \mathbf{f})$ determination of DCs, CD8+ T cells, macrophages and vessels around a fully occluded vessel (e) or partly occluded vessel (f) and the magnification of the indicated area (right) of the same a IPAH patient with extensive remodeling and immune cell infiltration. Data shown are representative for 6 IPAH patients. Sporadic CD206+CD68- cells with a morphology suggesting neutrophil identity were not regarded as DCs. Scale in left panels is $100 \mu \mathrm{m}$ and of right panels $50 \mu \mathrm{m}$. Arrows indicate DC and CD8 co-localization. 
In IPAH lungs, remodeling of pulmonary vessels was evident from the prominent staining with $\alpha$-SMA (Figure 5c,e). In the lungs of all six IPAH patients analyzed, macrophages were present, and in two patients the numbers were high, forming dense macrophages infiltrates. DCs were abundantly detectable as CD68-CD206+ cells in lung tissue of all six IPAH patients, although their presence in the parenchyma and around arterioles varied between patients. Figure 5 shows two representative patients, one patient with limited remodeling (panel c, d) and one patient with more severe remodeling (panel e, f). Close proximity of DCs and CD8+ T cells, indicative for DC-CD8+ T cell interaction, was mostly observed near affected, partly occluded vessels, but less frequently near fully occluded vessels (Figure 5c-f, shown in higher magnification in the right panel). Macrophages (CD206+CD68+) were particularly present near fully occluded vessels. Notably, in IPAH lungs with extensive remodeling and immune cell infiltration, co-localization of DCs and CD8+ T cells was most prominent. IPAH patient 2 had more remodeling and showed more DC and CD8 interaction than IPAH patient 1 , in which remodeling of the vessels was less severe.

In conclusion, these findings demonstrate close proximity of DCs and CD8+ T cells around vessels and in parenchyma in lungs of Tnfaip $3^{D N G R 1-K O}$ mice and IPAH patients, supporting a role for $\mathrm{CDC} 1 \mathrm{~s}$ in $\mathrm{PAH}$ pathology.

\section{Discussion}

We have previously shown that targeted deletion of the Tnfaip3 gene, encoding the NF- $\kappa$ B regulator A20, specifically in type I conventional dendritic cells (cDC1s), is sufficient to induce PAH symptoms in mice. In this study, we investigated the importance of the altered activation status of DCs in the development of PH.

We show that the heart, predominantly the RV, of Tnfaip $3^{D N G R 1-K O}$ mice is infiltrated with MHCII+CD11c+ DCs, CD19+ B cells and CD3+ T cells. Exposing 11-13-week-old Tnfaip3 ${ }^{D N G R 1-K O}$ mice to an additional TLR trigger did not lead to increased RV pressures and thereby a full PH phenotype. However, LPS exposure did induce hypertrophy of the $\mathrm{RV}$ and an altered activation of specifically cDC1s. We also found that adding a vascular trigger by reducing BMPRII expression in older Tnfaip $3^{D N G R 1-K O}$ mice did not result in an enhanced $\mathrm{PH}$ phenotype. As in our Tnfaip3 ${ }^{D N G R 1-K O}$ mouse model the Dngr1-credriven deletion mostly targets $\mathrm{cDC1}$, our findings indicate a key role of these cells in PAH development, which cannot be modulated by additional innate immune activation or defective BMPRII function in structural cells. cDC1s excel in cross presentation and thereby predominately interact with CD8+ T cells. DCs and T cells were mostly present near the small-to-mid-sized pulmonary vessels in Tnfaip $3^{D N G R 1-K O}$ and WT mice. Importantly, this was confirmed by the presence of DCs in close proximity to CD8+ T cells mostly around affected, but not fully occluded, pulmonary vessels in the lungs of IPAH patients.

We demonstrate that immune cells are not only present in the lungs of Tnfaip $3^{D N G R 1-K O}$ mice [27], but also in the heart, and especially in the RV. Using flow cytometry, we found higher frequencies of lymphocytes in the RV than in the LV of the hearts from both Tnfaip $3^{D N G R 1-K O}$ and WT mice. Histological analysis of DCs in the RV showed more pronounced differences between WT and Tnfaip $3^{D N G R 1-K O}$ mice than was seen by flow cytometry. An explanation might be that large local differences within RV regions exist between two mouse groups, which may be obscured in an analysis of whole RV cell suspensions, as is performed in flow cytometry. The RV is the ventricle that is enlarged in PAH and immune cells may be crucial in its remodeling and enlargement. However, it cannot be excluded that the influx of immune cells is a bystander effect, next to a primary process in the heart. Although the current knowledge on the presence of immune cells in the hearts of PAH patients is limited (reviewed in [32]), it has been shown that immune cells are increased in the hearts of SSc-PAH and IPAH patients compared to controls [33]. In SSc-PAH patients, immune cells were predominantly increased in the RV, but DCs were not specifically analyzed [33].

In our Tnfaip3 $3^{D N G R 1-K O}$ mice, a large part of the cardiac CD45+ cells consisted of DCs. Moreover, we found that DCs were present in the RV before pressures in the RV 
were elevated. To our knowledge, this is the first study that shows increased presence of myocardial DCs in an inflammatory-driven murine model for PH. Further studies are necessary to investigate if this increased presence of myocardial DCs is also found in the heart of PAH patients.

A large proportion of the CD45+ hematopoietic cells appeared to be neither T cells, B cells nor DCs, but might be macrophages or monocytes, since these cells comprise a large population in the heart, both in health and disease (reviewed in [34,35]). Macrophages are implicated in PAH [25,28], possibly by inflammasome-dependent secretion of pro-inflammatory cytokines such as IL-1 $\beta$ and IL-18 [36,37], which are increased in serum of PAH patients [15]. Interestingly, it has been found in mice that A20-deficient macrophages show spontaneous inflammasome activity and IL-1 $\beta$ secretion [38,39]. It is therefore conceivable that in Tnfaip $3^{D N G R 1-K O}$ mice, cDC1s also exhibit increased inflammasome activity and IL- $1 \beta$ secretion, and that A20-deficient cDC1s might therefore parallel pathogenic macrophages in PAH. However, it is also attractive to speculate that increased inflammasome-dependent IL-1 $\beta$ secretion stimulates potent cytotoxic $\mathrm{T}$ cell responses by $\mathrm{CD} 8+\mathrm{T}$ cells, as was very recently reported in the context of anti-tumor immunity [40]. Further experiments are required to investigate the role of inflammasome activation in DC-T cell interaction in inflamed lymph nodes as well as in local myocardial inflammation in Tnfaip $3^{D N G R 1-K O}$ mice.

Although 31-week-old Tnfaip $3^{D N G R 1-K O}$ mice show signs of $\mathrm{PH}$, these are absent in young Tnfaip $3^{D N G R 1-K O}$ mice. We wondered whether additional triggers would lead to increased $\mathrm{RV}$ pressures in young Tnfaip $3^{D N G R 1-K O}$ mice. It is believed that in order to develop PAH, a second trigger might be needed. For example, a viral infection alone is unlikely to cause PAH, since only one in 200 AIDS patients and only $10 \%$ of Hepatitis C patients show signs of PAH [13]. Therefore, we exposed 11-13-week-old Tnfaip $3^{D N G R 1-K O}$ mice to TLR3, TLR4 and TLR9 triggers, but none of these led to increased RV pressures within 2 weeks after the last exposure. These findings indicate that the alterations in the A20-deficient DCs were already sufficient to induce increased pressures over time, and that RVSP was not substantially enhanced by the TLR triggers investigated. Although there was no significant increase in pressure, TLR4 triggering by LPS resulted in RV hypertrophy and had effects, even two weeks after the last triggering, on the activation phenotype of cDC1s in the Tnfaip $3^{D N G R 1-K O}$ mice, but not in WT mice. The in vivo exposure to LPS increased CD40 expression and reduced PD-L1 expression on cDC1s in the lungs of Tnfaip $3^{D N G R 1-K O}$ mice. In in vitro experiments, it has been demonstrated that activation of DCs by LPS can prime DCs for subsequent signals from T cells [41]. The observed increase in CD40 expression and decrease in PD-L1 expression on Tnfaip $3^{\text {DNGR1-KO }} \mathrm{CDC1s}$ suggest a prolonged CD8+ T cell priming capacity of these CDC1s: at least up to two weeks after LPS exposure.

Reduced BMPRII signaling as an additional trigger in an inflammatory-based 31-weekold Tnfaip $3^{D N G R 1-K O}$ mouse model did not result in an enhanced $\mathrm{PH}$ phenotype. This might be related to the mild PH phenotype seen in Bmpr $2^{+/ R 899 X}$ mice [31]. Bmpr2 ${ }^{+/ R 899 X}$ mice do show increased RV pressures at 6 months of age, but do not have an increased Fulton index, indicating that there is no RV hypertrophy. In our hands, however, the $B m p r 2^{+/ R 899 X}$ mouse model did not display detectable increased RV pressures but did show remodeling of the pulmonary arteries and a higher Fulton index compared to WT controls. We did not find evidence for an additional effect of reduced BMPRII signaling on the immune system. The Bmpr2 $2^{+/ R 899 X}$ mice showed no apparent changes in DCs, T cells or B cells. It was quite unexpected that there were no signs of altered immunity in the $B m p r 2^{+/ R 899 X}$ mice, since it is known that BMPRII deficiency leads to the recruitment of lymphocytes, macrophages and neutrophils to the vessels [6]. Because there is a genotype-phenotype relationship regarding Bmpr2 mutations [30], it might be that this is also the case for immune involvement. Therefore, we cannot exclude that a more severe BMPRII-deficient PH mouse model may display changes in the immune system and may enhance the $\mathrm{PH}$ symptoms in Tnfaip $3^{D N G R 1-K O}$ mice. 
In our immunohistochemical analyses, the lungs of Tnfaip $3^{D N G R 1-K O}$ mice showed more CD3+ T cells and DCs than WT mice, mostly around vessels. These DCs and T cells might contribute to vessel remodeling, which is the major hallmark of PAH pathology. DCs are not only able to activate and attract pathogenic T cells, but also produce cytokines and chemokines such as IL-6 or CXCL13 [20]. Hereby, DCs may have a direct effect on the pulmonary vessels, since IL-6 may promote smooth muscle cell migration. Moreover, DCs may act indirectly by attracting other immune cells, for example B cells that may develop into plasma cells producing auto-antibodies recognizing endothelial epitopes. Likewise, attracted T cells may produce cytokines such as IL-17 that enhance fibroblast proliferation and collagen production [20]. In WT and Tnfaip $3^{D N G R 1-K O}$ mice, only a minor fraction of the $\mathrm{T}$ cells in the lung appeared to be CD8+ T cells. This was in contrast to the lungs of IPAH patients, in which both CD8+ T cells and DCs were abundantly present, even though we noticed heterogeneity among the IPAH patients. It is known that DCs expressing mannose receptors (CD209) are increased in lung tissue of IPAH patients, compared to control tissues [25]. The presence of DCs around pulmonary vessels has been shown before [17], but it remained unknown whether at this location they would also interact with $\mathrm{T}$ cells. We found that in the lung tissue of IPAH patients, many DCs localized adjacent to CD8+ T cells. Interestingly, this co-localization was particularly observed near affected, not fully occluded vessels, but to a lesser extent near fully occluded and remodeled vessels. This might be explained by the role of DCs and CD8+ T cells in the process of inflammation and remodeling, which may be less present in fully occluded vessels [17]. Since cDC1s are known to have the capacity to interact and activate CD8+ T cells, the DCs adjacent to CD8+ $\mathrm{T}$ cells in the IPAH lungs are most likely cDC1s. However, additional markers such as IRF8 are needed to determine if these cells are indeed cDC1s.

To be able to explore synergistic effects on PH development in Tnfaip $3^{D N G R 1-K O}$ mice, we chose a physiological model of BMPRII reduction, as this is a mild PH model that leaves a window for detection of an increase in disease severity. Although the $B m p r 2^{+/ R 899 X}$ mice showed remodeling of the pulmonary vessels and an increase in Fulton index, we did not measure increased RV pressures. Therefore, it remains possible that we were unable to detect $\mathrm{PH}$ enhancement in Tnfaip $3^{\text {DNGR1-KO }} \times \mathrm{X} \mathrm{Bmpr}^{+/ R 899 \mathrm{X}}$ mice was due to absence of full $\mathrm{PH}$ symptoms in the Bmpr $2^{+/ R 899 X}$ mice. On the other hand, it might be challenging to detect synergistic effects using a severe $\mathrm{PH}$ model, such as $\mathrm{PH}$ triggered by monocrotaline-induced endothelial damage or a more severe BMPRII-deficient PH mouse model [30,42].

Using the model of TLR4 triggering by LPS in the Tnfaip $3^{D N G R 1-K O}$ mice, we observed vascular remodeling and RV hypertrophy, but not an increase in RVSP. However, we observed a trend of increased RVSP in Tnfaip $3^{D N G R 1-K O}$ mice which did not reach significance. In this context, a limitation of our study is that it remains unclear whether multiple exposures of LPS, an analysis at later time points after LPS exposure, or exposure to TLR ligands other than LPS, CpG or Poly I:C would reveal more pronounced changes in RVSP in Tnfaip $3^{D N G R 1-K O}$ mice.

Taken together, our findings in Tnfaip $3^{D N G R 1-K O}$ mice suggest an important role of cDC1s in PAH pathogenesis, independent of general immune activation or a mutation in the Bmpr2 gene. This unique role includes the engagement of CD8+ T cells, given the observed co-localization of DCs and CD8+ T cells around vessels in the lungs of aged Tnfaip $3^{D N G R 1-K O}$ mice with PH symptoms and in the lungs of IPAH patients. Deeper knowledge about the functional role of DC subsets in the activation of T cells in PAH improves our understanding of PAH pathobiology and is expected to contribute to the identification of candidate therapeutical targets.

\section{Materials and Methods}

\subsection{Mice}

Tnfaip3 $3^{D N G R 1-K O}$ mice $\left(C l e c 9 a^{+/ C r e} \times\right.$ Tnfaip $\left.3^{f l f f l}\right)$ have been described previously $[27,43]$. Tnfaip $3^{\text {DNGR1-WT }}$ mice $\left(C l e c 9 a^{+/ \text {non-cre }} \times\right.$ Tnfaip $\left.3^{f l f l}\right)$ littermates served as WT controls. Mice 


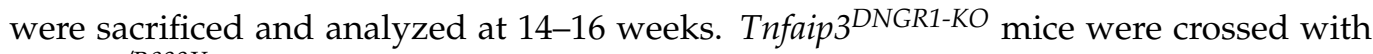
$B m p r 2^{+/ R 899 X}$ mice, which have a premature stop codon in the Bmpr 2 gene leading to reduced BMPRII expression [31]. In the experiments, four groups of mice were analyzed: WT, single Bmpr $2^{+/ R 899 X}$ mice, single Tnfaip $3^{\text {DNGR1-KO }}$ and Bmpr $2^{+/ R 899 X} \times$ Tnfaip $3^{\text {DNGR1-KO }}$ mice. Mice were sacrificed and analyzed when 31 weeks old. Mice were bred and housed at the Erasmus MC under SPF conditions. Experiments were approved by the animal ethical committee of the Erasmus MC, Rotterdam, The Netherlands.

\subsection{Exposure of TLR Ligand in Tnfaip $3^{\text {DNGR1-KO }}$ Mice}

For exposure to TLR ligands, $11-13$-week-old Tnfaip $3^{D N G R 1-K O}$ and Tnfaip $3^{D N G R 1-W T}$ mice were anesthetized using $2.5 \%$ isoflurane and subsequently administered intratracheally (i.t.) either 10-25 $\mu$ g CpG (ODN 1668, Invitrogen, Waltham, MA, USA), 40-100 $\mu \mathrm{g}$ Poly I:C (Invivogen, San Diego, CA, USA), $10 \mu \mathrm{g}$ LPS (Sigma-Aldrich, St. Louis, $\mathrm{MO}, \mathrm{USA})$ or $0.9 \%$ sodium chloride $(\mathrm{NaCl})$ at day 0 and day 7 . Mice were weighed daily and sacrificed at day 14 for analysis.

\subsection{Right Heart Catheterization and Fulton Index}

To determine RV pressures, mice were weighed and anesthetized by an intraperitoneal (i.p.) injection with urethane $(2 \mathrm{mg} / \mathrm{g}$, given according to weight of the mice). Urethane was used since this anesthetic has a minimal effect on the cardiovascular and respiratory system. After placing a tracheal canula (miniVent type 845, Hugo Sachs Elektronik, MarchHugstetten, Germany) the RV pressure was measured using a pressure catheter (Miller Inc., Houston, TX, USA), as described previously [27]. WinDaq (DataQ Instruments inc., Akron, OH, USA) and Matlab (the Mathworks inc., Natick, MA, USA) were used to record and analyze pressures. After excision of the heart, RV and left ventricle (LV) + septum (S) were separated and weighted separately [27]. The Fulton index was calculated by dividing the weight of the RV by the weight of $\mathrm{LV}+\mathrm{S}$.

\subsection{RNA Extraction Real-Time Quantitative RT-PCR}

Heart tissue (after separation of RV and LV/S) of Tnfaip $3^{D N G R 1-W T / K O}$ mice was stored in $-80^{\circ} \mathrm{C}$ until processing of the material. Heart tissue was homogenized using lysis buffer with 2-mercaptoethanol and $\frac{1}{4}$ " ceramic spheres (MP biomedicals, 6540-034) by shaking for $40 \mathrm{~s}$ (MP biomedicals, Fastprep-24 5G). Subsequently, RNA was extracted using TRI reagent (Sigma-Aldrich, T9424) and cDNA synthesis was performed using a RevertAid H minus First Strand cDNA synthesis Kit (Thermo Fisher Scientific, K1632, Waltham, MA, USA). The cDNA was used to measure expression of CD11c, BATF3, CD4 and CD8, as well as the Glyceraldehyde-3-phosphate dehydrogenase (GAPDH) housekeeping gene by RT-PCR in a 7300 Real time PCR system (Applied Biosystems, Foster City, CA, USA). Primer sequences are given in Supplementary Table S1.

\subsection{Histology of Lung and Heart Tissues}

Five- $\mu \mathrm{m}$-thick paraffin-embedded mouse lung sections were stained with hematoxylin and eosin (H\&E). Sections were stained for alpha smooth muscle actin ( $\alpha$-SMA) using mouse anti-human $\alpha$-SMA-PE (R\&D Systems, Minneapolis, MN, USA) and goat anti-PEalkaline phosphatase (Rockland, Limerick, PA, USA) as primary and secondary antibody, respectively. Antibodies used for immunohistochemical staining are listed in Supplementary Table S2. Prior to $\alpha$-SMA staining, antigen retrieval was performed by incubating slides in citrate buffer (PH 6.0, Sigma-Aldrich C9999-1000MC) at $78^{\circ} \mathrm{C}$ for $10 \mathrm{~min}$. Elastin van Gieson (EvG) staining (Elastic Stain kit (HT25), Sigma-Aldrich) was performed, according to manufacturer's instructions. To determine co-localization of CD11c with either CD3+ or CD8+ T cells, lung slides were first stained with hamster anti-mouse CD11c PE (clone N418, Thermo Fisher Scientific) and rat anti-mouse CD3 APC-ef780 (clone 17A2, Thermo Fisher Scientific), or rat anti-mouse CD8 Fitc (clone 53-6.7, BD Bioscience, San Jose, CA, 
USA). Next, slides were stained by secondary antibodies goat anti-PE-alkaline phosphatase (Rockland) and goat anti-rat PE (Sigma-Aldrich).

Mouse hearts were either directly separated after section and embedded for whole mount analyses of the RV or fixed in total with $4 \%$ paraformaldehyde (PFA) (Carl Roth, Karlsruge, Germany) before paraffin embedding. Five- $\mu \mathrm{m}$-thick paraffin-embedded heart sections were stained with EVG. For the evaluation of DCs in the heart, whole mount RVs were analysed. Directly after separation of the left ventricle/septum, the RV was pinned and fixed overnight using fresh $4 \%$ PFA/PBS. The next day, the RVs were washed and incubated with the primary antibody specific for MHCII and GFP (antibody details in Supplementary Table S2). After $24 \mathrm{~h}$, the RVs were washed and incubated with the secondary antibody. Finally, the RVs were embedded and analysed using a meta311 confocal microscope.

For immunohistochemical analysis of human lung tissue, we performed a 4-plex chromogenic multiplex by automated IHC using the Ventana Benchmark Discovery ULTRA (Ventana Medical Systems Inc., Tucson, AZ, USA). Study patients were either part of the French Network on Pulmonary Hypertension, a program approved by the institutional Ethics Committee (Protocol N8CO-08-003, ID RCB: 2008-A00485-50, approved on 18 June 2008) or were collected at the Erasmus MC Rotterdam and approved by the Medical Ethical Committee of the Erasmus MC Rotterdam (METC 2012-512). From all study patients, informed consent for collection of material was obtained. Slides of $4 \mu \mathrm{m}$ thick formalin-fixed paraffin-embedded (FFPE) sections were stained for CD8, CD68, $\alpha$-SMA and CD206. All antibodies are listed in Supplementary Table S2. In brief, following deparaffinization and heat-induced antigen retrieval with CC1 (\#950-224, Ventana) for $32 \mathrm{~min}$, anti-CD8 was incubated for $32 \mathrm{~min}$ at $37^{\circ} \mathrm{C}$ followed by omnimap anti-rabbit HRP (\#760-4311, Ventana) and detection with chromomap DAB (\#760-159, Ventana). An antibody denaturation step was performed with CC2 (\#950-123, Ventana) at $100{ }^{\circ} \mathrm{C}$ for $20 \mathrm{~min}$. Secondly, incubation with anti-CD68 was performed for 16 min at $37^{\circ} \mathrm{C}$, followed by omnimap anti-mouse HRP (\#760-4310, Ventana) and detection with Discovery Purple (\#760-229, Ventana) for $32 \mathrm{~min}$. An antibody denaturation step was performed with CC2 at $100{ }^{\circ} \mathrm{C}$ for $20 \mathrm{~min}$. Thirdly, anti- $\alpha$-SMA was incubated for $32 \mathrm{~min}$ at $37^{\circ} \mathrm{C}$, followed by omnimap anti-mouse HRP (\#760-4310, Ventana) and detection with Discovery Green (\#760-271, Ventana) for respectively 32 and $16 \mathrm{~min}$. An antibody denaturation step was performed with $\mathrm{CC} 2$ at $100{ }^{\circ} \mathrm{C}$ for $20 \mathrm{~min}$. Lastly, sections were incubated with anti-CD206 for $32 \mathrm{~min}$ at $37^{\circ} \mathrm{C}$ followed by mouse-NP (\#760-4816, Ventana) for $24 \mathrm{~min}$ at $37^{\circ} \mathrm{C}$ and subsequently anti-NP-AP (\#760-4827, Ventana) for $16 \mathrm{~min}$ and detection with Discovery Yellow (\#760-239, Ventana) for $44 \mathrm{~min}$. Incubation was followed by hematoxylin II counter stain for $4 \mathrm{~min}$ and then a blue coloring reagent for $4 \mathrm{~min}$ according to the manufacturer's instructions (Ventana).

\subsection{Flow Cytometry}

To obtain single-cell suspensions, lung and heart tissues were digested using DNase and Liberase at $37^{\circ} \mathrm{C}$ for $30 \mathrm{~min}$. After digestion, lungs and heart were homogenized through a $100-\mu \mathrm{m}$ cell strainer (BD Bioscience) and red blood cells were lysed using an osmotic lysis buffer. Flow cytometry extracellular and intracellular staining procedures have been described previously [44]. Dead cells were excluded using Fixable Viability Dye Live/Dead eF506 (eBioscience, San Diego, CA, USA). Monocloncal antibodies used are listed in Supplementary Table S3. Data was acquired using an LSR II flow cytometer (Beckton Dickinson, Franklin Lakes, NJ, USA) with FACS software (Beckton Dickinson). Data analysis was performed using FlowJo version 10 (Tree Star Inc software, Ashland, OR, USA).

\subsection{Statistic Analysis}

For comparisons between Tnfaip $3^{D N G R 1-W T}$ and Tnfaip $3^{D N G R 1-K O}$ mice, or between the TLR stimulation and $\mathrm{NaCl}$ stimulation, a Mann-Whitney $\mathrm{U}$ test was used. For comparisons

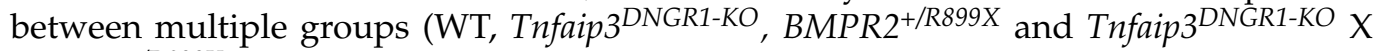
$B M P R 2^{+/ R 899 X}$ mice) a Kruskal-Wallis test was used, in combination with a Dunn's multi- 
ple comparison test comparing either mouse group to the WT mouse group or comparing all groups. $p$-values of $<0.05$ were considered statistically significant. Statistical analysis was performed using Prism 8 (GraphPad Software, V8.0, San Diego, CA, USA).

Supplementary Materials: The supplementary materials are available online at https:/ /www.mdpi. com/1422-0067/22/4/1756/s1.

Author Contributions: Conceptualization, D.v.U., T.K., M.K., K.A.B. and R.W.H.; formal analysis, D.v.U., T.K., C.G., J.H.v.d.T. and T.P.P.v.d.B.; investigation, D.v.U., T.K., J.A.C.v.H., I.M.B., C.G., J.H.v.d.T. and T.P.P.v.d.B.; methodology, D.v.U., T.K., M.K., K.A.B. and R.W.H.; resources, N.W.M., G.v.L., M.-R.G., F.P. and D.M.; supervision, M.K., K.A.B. and R.W.H.; visualization, D.v.U. and T.K.; writing—original draft, D.v.U., T.K., K.A.B. and R.W.H.; writing—review and editing, D.v.U., T.K., K.A.B. and R.W.H. All authors have read and agreed to the published version of the manuscript.

Funding: This research was funded by Dutch Heart Foundation, grant number 2016 T052 (D.v.U./ M.K.). T.K. was supported by an unrestricted grant by Actelion Pharmaceuticals and the Pulmonary hypertension Patients Association.

Institutional Review Board Statement: The study was conducted according to the guidelines of the Declaration of Helsinki, and approved by the Institutional Review Board of the French Network on Pulmonary Hypertension, a program approved by the institutional Ethics Committee (Protocol N8CO-08-003, ID RCB: 2008-A00485-50, approved on 18 June 2008) or by the Erasmus MC Rotterdam and approved by the Medical Ethical Committee of the Erasmus MC Rotterdam (METC 2012-512). Mice experiments were approved by the animal ethical committee of the Erasmus MC, Rotterdam, The Netherlands.

Informed Consent Statement: All subjects gave their written informed consent.

Data Availability Statement: The data presented in this study are available in this article and in the supplementary material.

Acknowledgments: We thank Caetano Reis e Sousa and Mark Toshner for providing critical mouse strains, Daphne Merkus for providing the millar for measuring the RV pressure and Madelief Vink for assistance during experiments. Finally, we thank the Erasmus Mc Animal Facility (EDC) staff for their assistance during the project.

Conflicts of Interest: D.M. reports grants of and personal fees from Actelion, grants and personal fees from Bayer, personal fees from GSK, personal fees from Pfizer, grants, personal fees and non-financial support from MSD, personal fees from Chiesi, personal fees from Boerhinger, non-financial support from Acceleron, personal fees from Incyte Biosciences France, outside the submitted work. All other authors declare no conflict of interest. The funders had no role in the design of the study; in the collection, analyses, or interpretation of data; in the writing of the manuscript or in the decision to publish the results.

\section{Abbreviations}

$\begin{array}{ll}\text { AM } & \text { Alveolar macrophages } \\ \text { BATF3 } & \text { Basic leucine zipper transcriptional factor ATF-like 3 } \\ \text { BMPR2 } & \text { Bone morphogenetic protein receptor type 2 } \\ \text { cDC1s } & \text { Type 1 conventional DCs } \\ \text { cDC2s } & \text { Type 2 conventional DCs } \\ \text { CTD-PAH } & \text { Connective tissue disease PAH } \\ \text { CXCL8 } & \text { X-X-C-motif chemokine ligand } 8 \\ \text { DCs } & \text { Dendritic cells } \\ \text { EvG } & \text { Elastic von Gieson } \\ \text { H\&E } & \text { Hematoxylin and eosin } \\ \text { HPAH } & \text { Heritable PAH } \\ \text { i.p. } & \text { Intraperitoneal } \\ \text { i.t. } & \text { Intratracheally }\end{array}$




$\begin{array}{ll}\text { IL } & \text { Interleukin } \\ \text { IM } & \text { Interstitial macrophages } \\ \text { IPAH } & \text { Idiopathic PAH } \\ \text { LPS } & \text { Lipopolysaccharide } \\ \text { LV } & \text { Left ventricle } \\ \text { Mo-DC } & \text { Monocyte-derived-DC } \\ \text { NaCl } & \text { Sodium chloride } \\ \text { NF-kB } & \text { Nuclear factor-kappa B } \\ \text { PAH } & \text { Pulmonary arterial hypertension } \\ \text { PAP } & \text { Pulmonary arterial pressure } \\ \text { PASMCs } & \text { Pulmonary artery smooth muscle cells } \\ \text { PH } & \text { Pulmonary hypertension } \\ \text { pDC } & \text { Plasmacytoid DC } \\ \text { PFA } & \text { paraformaldehyde } \\ \text { Poly I:C } & \text { Polyinosinic-polycytidylic acif high molecular weight } \\ \text { RV } & \text { Right ventricle } \\ \text { RVSP } & \text { Right ventricular systolic pressure } \\ \text { S } & \text { Septum } \\ \text { TGF } \beta & \text { Transforming growth factor- } \beta \\ \text { TLOs } & \text { Tertiary lymphoid organs } \\ \text { TLR } & \text { Toll like receptor } \\ \text { Tnfaip3 } & \text { TNF } \alpha \text {-induced protein-3 } \\ \text { WHO } & \text { World health organization } \\ \text { WT } & \text { Wild type } \\ \alpha \text {-SMA } & \text { Alpha smooth muscle actin } \\ & \end{array}$

\section{References}

1. Simonneau, G.; Montani, D.; Celermajer, D.S.; Denton, C.P.; Gatzoulis, M.A.; Krowka, M.; Williams, P.G.; Souza, R. Haemodynamic definitions and updated clinical classification of pulmonary hypertension. Eur. Respir. J. 2019, 53, 1801913. [CrossRef] [PubMed]

2. Southgate, L.; Machado, R.D.; Graf, S.; Morrell, N.W. Molecular genetic framework underlying pulmonary arterial hypertension. Nat. Rev. Cardiol. 2020, 17, 85-95. [CrossRef]

3. Morrell, N.W.; Aldred, M.A.; Chung, W.K.; Elliott, C.G.; Nichols, W.C.; Soubrier, F.; Trembath, R.C.; Loyd, J.E. Genetics and genomics of pulmonary arterial hypertension. Eur. Respir. J. 2019, 53, 1801899. [CrossRef]

4. Atkinson, C.; Stewart, S.; Upton, P.D.; Machado, R.; Thomson, J.R.; Trembath, R.C.; Morrell, N.W. Primary pulmonary hypertension is associated with reduced pulmonary vascular expression of type II bone morphogenetic protein receptor. Circulation 2002, 105, 1672-1678. [CrossRef]

5. Machado, R.D.; Southgate, L.; Eichstaedt, C.A.; Aldred, M.A.; Austin, E.D.; Best, D.H.; Chung, W.K.; Benjamin, N.; Elliott, C.G.; Eyries, M.; et al. Pulmonary Arterial Hypertension: A Current Perspective on Established and Emerging Molecular Genetic Defects. Hum. Mutat. 2015, 36, 1113-1127. [CrossRef]

6. Andruska, A.; Spiekerkoetter, E. Consequences of BMPR2 Deficiency in the Pulmonary Vasculature and Beyond: Contributions to Pulmonary Arterial Hypertension. Int. J. Mol. Sci. 2018, 19, 2499. [CrossRef]

7. Elinoff, J.M.; Mazer, A.J.; Cai, R.; Lu, M.; Graninger, G.; Harper, B.; Ferreyra, G.A.; Sun, J.; Solomon, M.A.; Danner, R.L. Metaanalysis of blood genome-wide expression profiling studies in pulmonary arterial hypertension. Am. J. Physiol. Cell. Mol. Physiol. 2020, 318, L98-L111. [CrossRef] [PubMed]

8. Xiao, G.; Zhuang, W.; Wang, T.; Lian, G.; Luo, L.; Ye, C.; Wang, H.; Xie, L. Transcriptomic analysis identifies Toll-like and Nod-like pathways and necroptosis in pulmonary arterial hypertension. J. Cell. Mol. Med. 2020, 24, 11409-11421. [CrossRef] [PubMed]

9. Zhao, E.; Xie, H.; Zhang, Y. Identification of Differentially Expressed Genes Associated with Idiopathic Pulmonary Arterial Hypertension by Integrated Bioinformatics Approaches. J. Comput. Biol. 2021. [CrossRef]

10. Chesne, J.; Danger, R.; Botturi, K.; Reynaud-Gaubert, M.; Mussot, S.; Stern, M.; Danner-Boucher, I.; Mornex, J.F.; Pison, C.; Dromer, C.; et al. Systematic analysis of blood cell transcriptome in end-stage chronic respiratory diseases. PLoS ONE 2014, 9 , e109291. [CrossRef]

11. George, P.M.; Badiger, R.; Shao, D.; Edwards, M.R.; Wort, S.J.; Paul-Clark, M.J.; Mitchell, J.A. Viral Toll Like Receptor activation of pulmonary vascular smooth muscle cells results in endothelin-1 generation; relevance to pathogenesis of pulmonary arterial hypertension. Biochem. Biophys. Res. Commun. 2012, 426, 486-491. [CrossRef] [PubMed]

12. Collin, M.; Bigley, V. Human dendritic cell subsets: An update. Immunology 2018, 154, 3-20. [CrossRef]

13. Cool, C.D.; Voelkel, N.F.; Bull, T. Viral infection and pulmonary hypertension: Is there an association? Expert Rev. Respir. Med. 2011, 5, 207-216. [CrossRef]

14. Kubrycht, J.; Novotna, J. Sequence-based prediction of linear autoepitopes involved in pathogenesis of IPAH and the corresponding organism sources of molecular mimicry. Int. J. Bioinform. Res. Appl. 2014, 10, 587-612. [CrossRef] 
15. Soon, E.; Holmes, A.M.; Treacy, C.M.; Doughty, N.J.; Southgate, L.; Machado, R.D.; Trembath, R.C.; Jennings, S.; Barker, L.; Nicklin, P.; et al. Elevated levels of inflammatory cytokines predict survival in idiopathic and familial pulmonary arterial hypertension. Circulation 2010, 122, 920-927. [CrossRef]

16. Sweatt, A.J.; Hedlin, H.K.; Balasubramanian, V.; Hsi, A.; Blum, L.K.; Robinson, W.H.; Haddad, F.; Hickey, P.M.; Condliffe, R.; Lawrie, A.; et al. Discovery of Distinct Immune Phenotypes Using Machine Learning in Pulmonary Arterial Hypertension. Circ. Res. 2019, 124, 904-919. [CrossRef] [PubMed]

17. Perros, F.; Dorfmuller, P.; Montani, D.; Hammad, H.; Waelput, W.; Girerd, B.; Raymond, N.; Mercier, O.; Mussot, S.; CohenKaminsky, S.; et al. Pulmonary lymphoid neogenesis in idiopathic pulmonary arterial hypertension. Am. J. Respir. Crit. Care Med. 2012, 185, 311-321. [CrossRef] [PubMed]

18. GeurtsvanKessel, C.H.; Willart, M.A.; Bergen, I.M.; van Rijt, L.S.; Muskens, F.; Elewaut, D.; Osterhaus, A.D.; Hendriks, R.; Rimmelzwaan, G.F.; Lambrecht, B.N. Dendritic cells are crucial for maintenance of tertiary lymphoid structures in the lung of influenza virus-infected mice. J. Exp. Med. 2009, 206, 2339-2349. [CrossRef]

19. Halle, S.; Dujardin, H.C.; Bakocevic, N.; Fleige, H.; Danzer, H.; Willenzon, S.; Suezer, Y.; Hammerling, G.; Garbi, N.; Sutter, G.; et al. Induced bronchus-associated lymphoid tissue serves as a general priming site for T cells and is maintained by dendritic cells. J. Exp. Med. 2009, 206, 2593-2601. [CrossRef] [PubMed]

20. van Uden, D.; Boomars, K.; Kool, M. Dendritic Cell Subsets and Effector Function in Idiopathic and Connective Tissue DiseaseAssociated Pulmonary Arterial Hypertension. Front. Immunol. 2019, 10, 11. [CrossRef]

21. Perros, F.; Dorfmuller, P.; Souza, R.; Durand-Gasselin, I.; Mussot, S.; Mazmanian, M.; Herve, P.; Emilie, D.; Simonneau, G.; Humbert, M. Dendritic cell recruitment in lesions of human and experimental pulmonary hypertension. Eur. Respir. J. 2007, 29, 462-468. [CrossRef] [PubMed]

22. Dorfmuller, P.; Chaumais, M.C.; Giannakouli, M.; Durand-Gasselin, I.; Raymond, N.; Fadel, E.; Mercier, O.; Charlotte, F.; Montani, D.; Simonneau, G.; et al. Increased oxidative stress and severe arterial remodeling induced by permanent high-flow challenge in experimental pulmonary hypertension. Respir. Res. 2011, 12, 119. [CrossRef] [PubMed]

23. Ranchoux, B.; Antigny, F.; Rucker-Martin, C.; Hautefort, A.; Pechoux, C.; Bogaard, H.J.; Dorfmuller, P.; Remy, S.; Lecerf, F.; Plante, S.; et al. Endothelial-to-mesenchymal transition in pulmonary hypertension. Circulation 2015, 131, 1006-1018. [CrossRef] [PubMed]

24. Hautefort, A.; Girerd, B.; Montani, D.; Cohen-Kaminsky, S.; Price, L.; Lambrecht, B.N.; Humbert, M.; Perros, F. T-helper 17 cell polarization in pulmonary arterial hypertension. Chest 2015, 147, 1610-1620. [CrossRef]

25. Marsh, L.M.; Jandl, K.; Grunig, G.; Foris, V.; Bashir, M.; Ghanim, B.; Klepetko, W.; Olschewski, H.; Olschewski, A.; Kwapiszewska, G. The inflammatory cell landscape in the lungs of patients with idiopathic pulmonary arterial hypertension. Eur. Respir. J. 2018, 51. [CrossRef]

26. Wang, W.; Yan, H.; Zhu, W.; Cui, Y.; Chen, J.; Wang, X.; Li, S.; Zhu, J. Impairment of monocyte-derived dendritic cells in idiopathic pulmonary arterial hypertension. J. Clin. Immunol. 2009, 29, 705-713. [CrossRef]

27. Koudstaal, T.; van Hulst, J.A.C.; Das, T.; Neys, S.F.H.; Merkus, D.; Bergen, I.M.; de Raaf, M.A.; Bogaard, H.J.; Boon, L.; van Loo, G.; et al. DNGR1-Cre-mediated Deletion of Tnfaip3/A20 in Conventional Dendritic Cells Induces Pulmonary Hypertension in Mice. Am. J. Respir. Cell Mol. Biol. 2020, 63, 665-680. [CrossRef]

28. Koudstaal, T.; Boomars, K.A.; Kool, M. Pulmonary Arterial Hypertension and Chronic Thromboembolic Pulmonary Hypertension: An Immunological Perspective. J. Clin. Med. 2020, 9, 561. [CrossRef] [PubMed]

29. Sabatel, C.; Radermecker, C.; Fievez, L.; Paulissen, G.; Chakarov, S.; Fernandes, C.; Olivier, S.; Toussaint, M.; Pirottin, D.; Xiao, X.; et al. Exposure to Bacterial CpG DNA Protects from Airway Allergic Inflammation by Expanding Regulatory Lung Interstitial Macrophages. Immunity 2017, 46, 457-473. [CrossRef] [PubMed]

30. Frump, A.; Prewitt, A.; de Caestecker, M.P. BMPR2 mutations and endothelial dysfunction in pulmonary arterial hypertension (2017 Grover Conference Series). Pulm. Circ. 2018, 8, 2045894018765840. [CrossRef]

31. Long, L.; Ormiston, M.L.; Yang, X.; Southwood, M.; Graf, S.; Machado, R.D.; Mueller, M.; Kinzel, B.; Yung, L.M.; Wilkinson, J.M.; et al. Selective enhancement of endothelial BMPR-II with BMP9 reverses pulmonary arterial hypertension. Nat. Med. 2015, 21, 777-785. [CrossRef]

32. Sun, X.Q.; Abbate, A.; Bogaard, H.J. Role of cardiac inflammation in right ventricular failure. Cardiovasc. Res. 2017, 113, 1441-1452. [CrossRef]

33. Overbeek, M.J.; Mouchaers, K.T.; Niessen, H.M.; Hadi, A.M.; Kupreishvili, K.; Boonstra, A.; Voskuyl, A.E.; Belien, J.A.; Smit, E.F.; Dijkmans, B.C.; et al. Characteristics of interstitial fibrosis and inflammatory cell infiltration in right ventricles of systemic sclerosis-associated pulmonary arterial hypertension. Int. J. Rheumatol. 2010, 2010, 604615. [CrossRef]

34. Swirski, F.K.; Nahrendorf, M. Cardioimmunology: The immune system in cardiac homeostasis and disease. Nat. Rev. Immunol. 2018, 18, 733-744. [CrossRef]

35. Zaman, R.; Hamidzada, H.; Epelman, S. Exploring cardiac macrophage heterogeneity in the healthy and diseased myocardium. Curr. Opin. Immunol. 2020, 68, 54-63. [CrossRef] [PubMed]

36. Siamwala, J.H.; Zhao, A.; Barthel, H.; Pagano, F.S.; Gilbert, R.J.; Rounds, S. Adaptive and innate immune mechanisms in cardiac fibrosis complicating pulmonary arterial hypertension. Physiol. Rep. 2020, 8, e14532. [CrossRef] [PubMed]

37. Latz, E.; Xiao, T.S.; Stutz, A. Activation and regulation of the inflammasomes. Nat. Rev. Immunol. 2013, 13, 397-411. [CrossRef] [PubMed]

38. Duong, B.H.; Onizawa, M.; Oses-Prieto, J.A.; Advincula, R.; Burlingame, A.; Malynn, B.A.; Ma, A. A20 restricts ubiquitination of pro-interleukin-1beta protein complexes and suppresses NLRP3 inflammasome activity. Immunity 2015, 42, 55-67. [CrossRef] 
39. Vande Walle, L.; Van Opdenbosch, N.; Jacques, P.; Fossoul, A.; Verheugen, E.; Vogel, P.; Beyaert, R.; Elewaut, D.; Kanneganti, T.D.; van Loo, G.; et al. Negative regulation of the NLRP3 inflammasome by A20 protects against arthritis. Nature 2014, 512, 69-73. [CrossRef]

40. Zhivaki, D.; Borriello, F.; Chow, O.A.; Doran, B.; Fleming, I.; Theisen, D.J.; Pallis, P.; Shalek, A.K.; Sokol, C.L.; Zanoni, I.; et al Inflammasomes within Hyperactive Murine Dendritic Cells Stimulate Long-Lived T Cell-Mediated Anti-tumor Immunity. Cell Rep. 2020, 33, 108381. [CrossRef]

41. Abdi, K.; Singh, N.J.; Matzinger, P. Lipopolysaccharide-activated dendritic cells: "exhausted" or alert and waiting? J. Immunol. 2012, 188, 5981-5989. [CrossRef] [PubMed]

42. Nogueira-Ferreira, R.; Vitorino, R.; Ferreira, R.; Henriques-Coelho, T. Exploring the monocrotaline animal model for the study of pulmonary arterial hypertension: A network approach. Pulm. Pharmacol. Ther. 2015, 35, 8-16. [CrossRef] [PubMed]

43. Schraml, B.U.; van Blijswijk, J.; Zelenay, S.; Whitney, P.G.; Filby, A.; Acton, S.E.; Rogers, N.C.; Moncaut, N.; Carvajal, J.J.; Reis e Sousa, C. Genetic tracing via DNGR-1 expression history defines dendritic cells as a hematopoietic lineage. Cell 2013, 154, 843-858. [CrossRef]

44. Vroman, H.; Bergen, I.M.; van Hulst, J.A.C.; van Nimwegen, M.; van Uden, D.; Schuijs, M.J.; Pillai, S.Y.; van Loo, G.; Hammad, H.; Lambrecht, B.N.; et al. TNF-alpha-induced protein 3 levels in lung dendritic cells instruct TH2 or TH17 cell differentiation in eosinophilic or neutrophilic asthma. J. Allergy Clin. Immunol. 2018, 141, 1620-1633.e12. [CrossRef] [PubMed] 